\title{
TIMING OF INTRODUCTION TO SOLID FOOD, GROWTH AND NUTRITION RISK IN LATER CHILDHOOD
}

by

\author{
Curtis D'Hollander
}

A thesis submitted in conformity with the requirements

for the degree of Master of Science

Department of Nutritional Sciences

University of Toronto

(C) Copyright by Curtis D’Hollander (2021) 


\title{
Timing of introduction to solid food, growth and nutrition risk in later childhood
}

\author{
Curtis D'Hollander \\ Master of Science \\ Department of Nutritional Sciences \\ University of Toronto \\ 2021
}

\begin{abstract}
It is recommended in Canada to introduce solid food at 6 months of age in keeping with the recommendations from the World Health Organization. The European Society for Paediatric Nutrition recommends solid food be introduced between 4 and 6 months of age. Few studies have differentiated between this period. In this thesis I aimed to evaluate the relationship between the timing of introduction to infant cereal as the first solid food between 4 and 6 months and growth and nutrition risk. Through a longitudinal study of healthy children participating in the TARGet Kids! cohort, introduction to infant cereal at 4 months, compared to 6 months, was associated with higher body mass index z-score and higher odds of obesity through 10 years of age, worse eating behaviour between 18 months and 5 years and minimal differences in height. These findings support guidelines for introducing solid food around 6 months of age.
\end{abstract}




\section{ACKNOWLEDGEMENTS}

Completing my master's degree has been a whirlwind. Few can say they completed their degree during a pandemic. I learned many key technical skills in writing, methodology, knowledge translation and nutritional science. Above all, I learned to persevere and the importance of a supportive team.

I am fortunate to have met Dr. Maguire and have him as my supervisor. I thank Dr. Maguire for his unwavering support and leadership through the up's and down's and expertise to produce a meaningful project. Additionally, it has been terrific to work with the TARGet Kids! research team and so many bright and inspiring scientisits and clinicians. I look forward to continuing to work with TARget Kids!.

I was surrounded by amazing mentors on my research committee. Thank you Dr. Birken, Dr. Keown-Stoneeman and Dr. O'Connor for challenging my way of thinking, your guidance and patience. I have a sound research foundation to build on thanks to you.

To the other trainees - Shelley, Izabela, Laura, Xuedi, Courtney, Michaela - thank you for sharing your knowledge, selflessness and encouragement.

Lastly, thank you to my family who have been patiently waiting to read this thesis. Your encouragement and validation have been instrumental in my success. Also, your flexibility in navigating unforeseen circumstances has been vital.

To everyone who has contributed to this thesis, directly and indirectly, I thank you. This was truly a team effort. 


\section{TABLE OF CONTENTS}

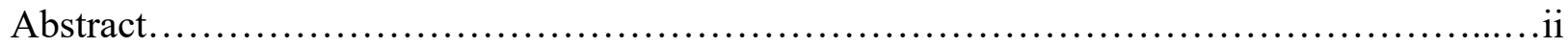

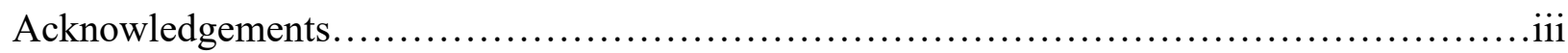

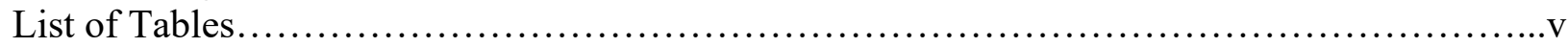

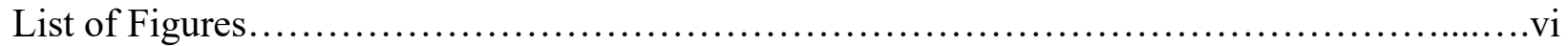

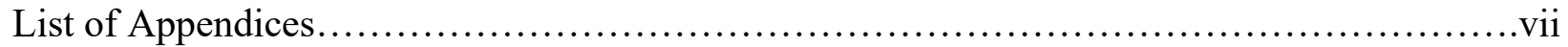

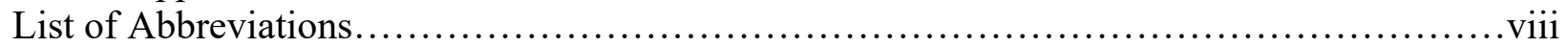

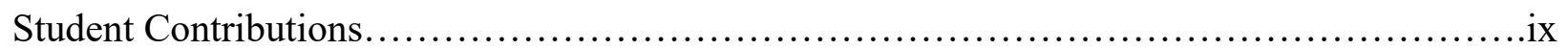

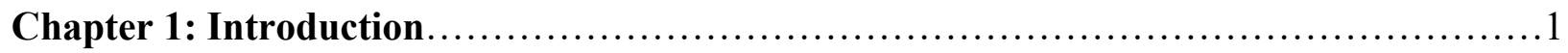

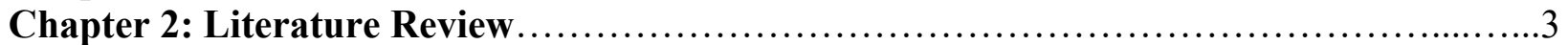

Section 1. Childhood growth and development............................................

1.1. Nutrition during infancy and life-long health....................................

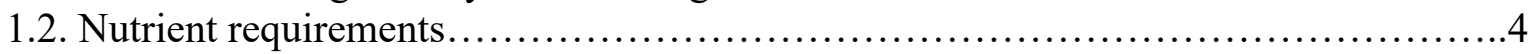

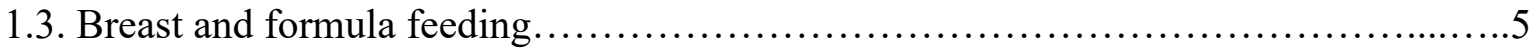

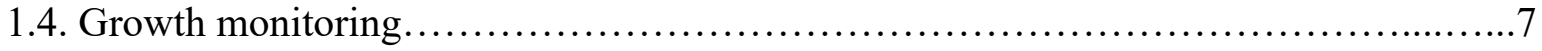

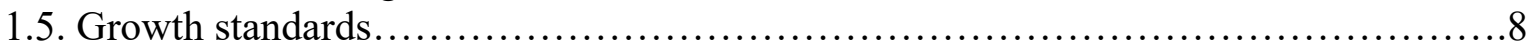

1.6. Childhood obesity in Canada................................................. 11

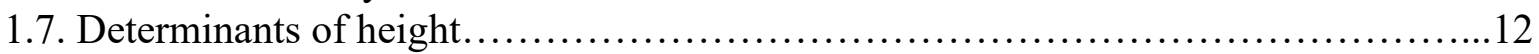

Section 2. Introduction to solid food in children......................................... 12

2.1. Physiological readiness for solid foods............................................12

2.2. WHO and international guidelines.............................................

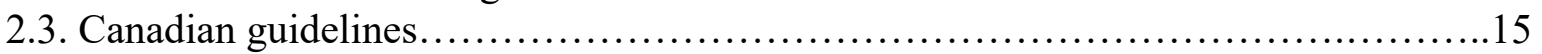

2.4. Timing of introduction to solid food in children...................................16

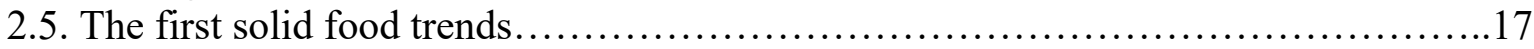

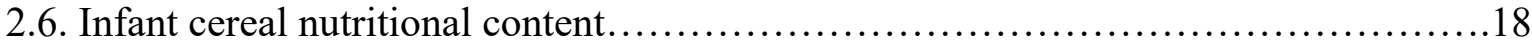

2.7. Caregiver feeding approaches............................................... 18

Section 3. Role of timing of introduction to solid food on growth and nutrition risk..........19

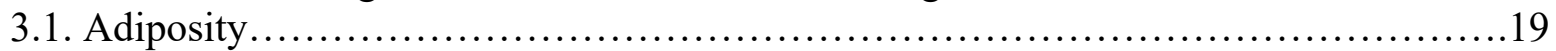

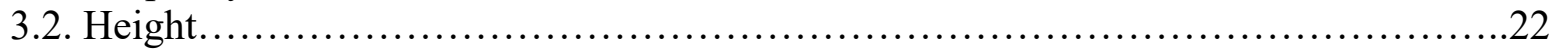

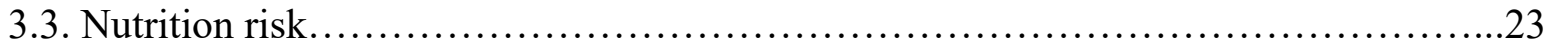

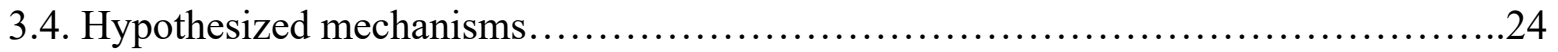

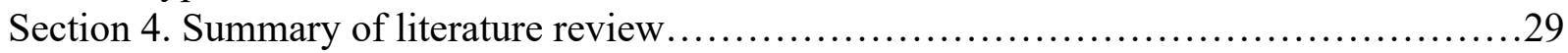

Chapter 3: Timing of introduction to solid food, growth and nutrition risk in later

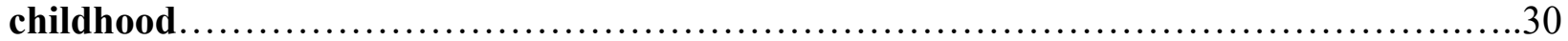

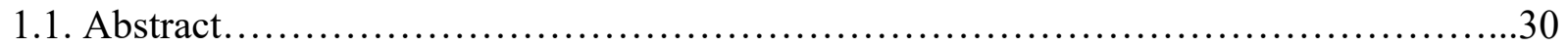

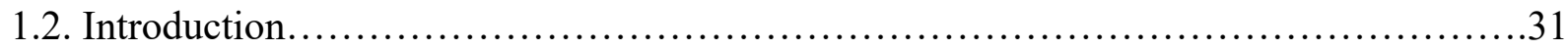

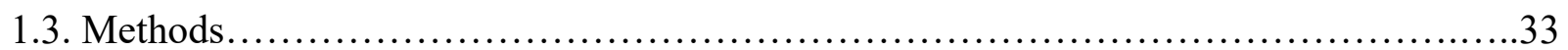

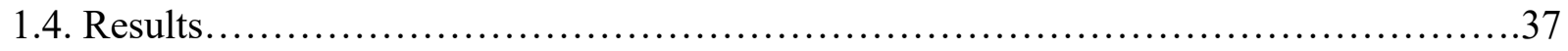

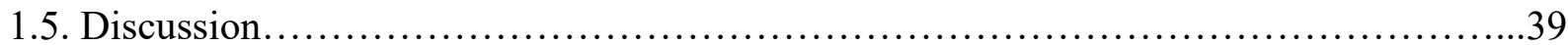

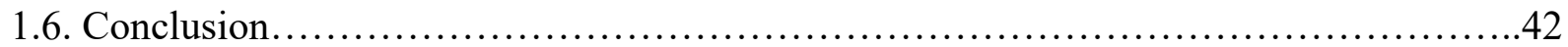

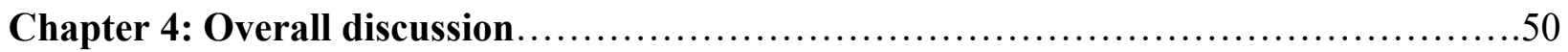

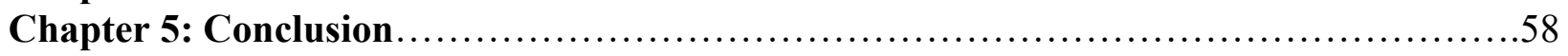

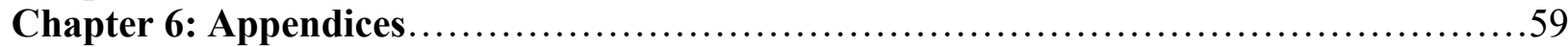

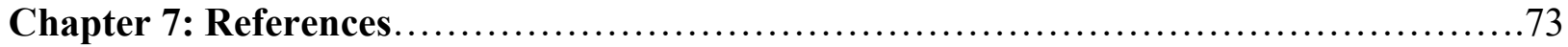




\section{LIST OF TABLES}

Table 1: Nutrition facts for breast milk and infant formula.............................

Table 2: BMI-for-age z-score and growth status based on WHO growth standard/reference.....10

Table 3: International guidelines for when to introduce solid foods.......................14

Table 4: Protein content of breast milk, infant formula and common first solid foods..........26

Table 5: Participant initial visit characteristics.......................................43

Table 6: Pairwise comparisons of introduction to infant cereal at 4 vs. 6 months of age and

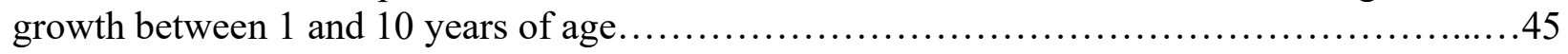

Table 7: Pairwise comparisons of introduction to infant cereal at 4 vs. 6 months of age and

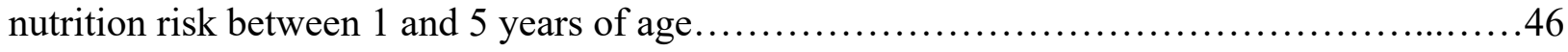




\section{LIST OF FIGURES}

Figure 1: Nutrition risk mediating the relationship between timing of introduction to solid food

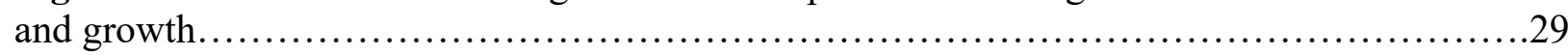

Figure 2: Participant flow chart............................................... 47

Figure 3: Association between time introduced to infant cereal (4-6 mo) and growth and

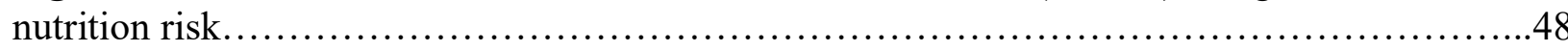

Figure 4: Timing of introduction to infant cereal (4-6 mo) pairwise comparisons by child age (y)

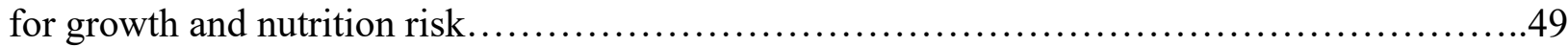




\section{LIST OF APPENDICES}

Appendix A: WHO child growth standards (0-5 year) and reference (5-19 years) - girls BMI-

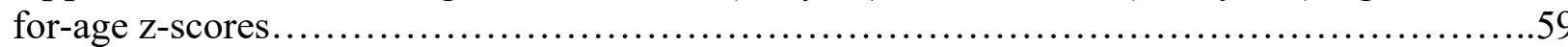

Appendix B: Summary of previous studies evaluating the relationship between the timing of introduction to solid food and growth.

Appendix C: Summary of previous studies evaluating the relationship between the timing of introduction to solid food and nutrition risk.

Appendix D: Nutrition and Health Questionairre (NHQ) provded to child's caregivers to determine time introduced to infant cereal...........................................64

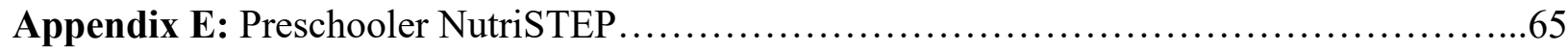

Appendix F: Data creation plan for original research study............................69 


\section{LIST OF ABBREVIATIONS}

AAP American Academy of Pediatrics

ADP Air Displacement Plethysmography

AI Adequate Intake

ALSPAC Avon Longitudinal Study of Parents and Children

BCPE Box-Cox-power-exponential

BLW Baby Led Weaning

BMI Body Mass Index

CCHS Canadian Community Health Survey

CPS Canadian Paediatric Society

CT Computed Tomography

DC Dietitians of Canada

DEXA Dual Energy X-Ray Absorptiometry

DRI Dietary Reference Intake

EAR Estimated Average Requirement

ESPGHAN European Society for Paediatric Gastroenterology, Hepatology and Nutrition

FITS Feeding Infants and Toddlers Study

GH Growth Hormone

IGF-1 Insulin-like Growth Factor-1

MACS Melbourne Atopy Cohort Study

MRI Magnetic Resonance Imaging

NutriSTEP Nutrition Screening Tool for Toddlers and Preschoolers

RCT Randomized Controlled Trial

SD Standard Deviation

SSB Sugar Sweetened Beverage

UK United Kingdom

US United States

zBMI Body Mass Index z-score

zHeight Length/Height-for-age z-score 


\section{STUDENT CONTRIBUTIONS}

- Conceptualized research questions, study design and analyses

- Cleaned the data and performed statistical analyses using the statistical program $\mathrm{R}$

- Wrote thesis

- Presented research findings:

- University of Toronto 3 minute thesis and St. Michael's Hospital elevator pitch competition $(2019 / 2020 / 2021)$

- Canadian Nutrition Society Thematic Conference (2020/2021)

- Pediatric Academic Societies Meeting (2021)

- Submitted research article for publication in JAMA Pediatrics 


\section{CHAPTER 1: INTRODUCTION}

Adequate nutrition during early life is important for optimal growth, development and long-term health. ${ }^{1,2}$ Enhancing early nutrition through modifiable factors such as the timing of solid food introduction could help to improve health outcomes throughout life. ${ }^{3}$

The timing of introduction to the first solid foods is a decision faced by all parents. Breast milk or infant formula alone are not adequate to sustain an infant's nutrient requirements beyond about 4-6 months of age. ${ }^{4,5}$ Thus, the introduction of nutrient dense solid foods is necessary. ${ }^{4}$ Health Canada and the Canadian Paediatric Society (CPS) recommend that solid foods be introduced around 6 months of age in keeping with the recommendations from the World Health Organization (WHO). ${ }^{4,6}$ However, recommendations for when solid foods should be introduced vary between countries and organizations. ${ }^{4-10}$ The United Kingdom (UK) and United States (US) also recommend solid foods be introduced around 6 months. ${ }^{7,8}$ The Netherlands and Sweden recommend that infants can receive solid foods or "small tastes" by 4 months of age and the European Society for Paediatric Gastroenterology, Hepatology, and Nutrition (ESPGHAN) recommend introducing solid food between 4 and 6 months of age. ${ }^{5,9,10}$

Introduction to solid food $<4$ and $>6$ months has been associated with an increase in body mass index (BMI) and problematic feeding behaviour in later childhood. ${ }^{11-13}$ However, little is known about how the introduction of solid food between 4 and 6 months of age is related to growth and feeding behaviour in later childhood. ${ }^{14}$ Differences in the timing of solid food introduction between 4 and 6 months of age could have important implications for growth and feeding behaviour in later childhood. 
The primary objective of this thesis was to evaluate the relationship between the timing of introduction to solid food between 4 and 6 months of age and BMI z-score among healthy children through 10 years of age. The secondary objectives were to examine the relationship between the timing of introduction to solid food between 4 and 6 months of age and: length/height-for-age z-score (zHeight) and nutrition risk.

This thesis is divided into 7 chapters. The current introduction (Chapter 1) is followed by a literature review (Chapter 2) which is divided into 3 sections: childhood growth and development; introduction to solid food in children; and role of timing of introduction to solid food on growth and nutrition risk. Following this is my original research: Timing of introduction to solid food, growth and nutrition risk in later childhood (Chapter 3). Lastly an overall discussion (Chapter 4), conclusion (Chapter 5), appendices (Chapter 6), and references (Chapter 7). 


\section{CHAPTER 2: LITERATURE REVIEW}

Section 1: Childhood growth and development

\subsection{Nutrition during infancy and life-long health}

Infancy is the period from birth to about 2 years of age characterized by rapid growth and development and many new milestones are achieved. ${ }^{15}$ During the first year of life, an infant learns how to stand, hold objects, communicate in various ways, and transitions from breast or bottle feeding to solid foods. ${ }^{15,16}$ This period is characterized by rapid growth with infants tripling their birthweight by 1 year of age. ${ }^{17,18}$ With this rapid growth comes high nutrient requirements and the potential for long lasting health consequences if these are not met. ${ }^{2}$

Nutrition during the first year of life is known to influence health in later life. For example, introduction of solid foods $<4$ months of age has been associated with more rapid weight gain and overweight in later childhood. ${ }^{19,20}$ Childhood overweight has been associated with diseases such as type 2 diabetes, asthma, cardiovascular disease and sleep apnea. ${ }^{21}$ Inadequate early life nutrition has been associated with lower adult height and cardiovascular disease risk factors. ${ }^{22-25}$

The first year of life is also an important time for the development of lifelong feeding behaviour. Early feeding experiences can affect the development of food preferences. ${ }^{26}$ For instance, repeated vegetable and fruit exposures can promote their acceptance. ${ }^{27}$ Earlier introduction to vegetables has been shown to result in greater consumption of vegetables later in childhood. ${ }^{28}$ Additionally, children with a preference for high-fat foods have been shown to have higher adiposity. ${ }^{29}$ 


\subsection{Nutrient requirements}

Canada has established Dietary Reference Intakes (DRI) for children 0-6 months and 7-12 months of age. ${ }^{30}$ These DRI's were established based on Adequate Intakes (AI), which is the estimated average nutrient intake of a healthy population, because there was not enough evidence to determine an Estimated Average Requirement (EAR), which is the intake level which meets the needs of $50 \%$ of the population. ${ }^{31}$ The AI for children $0-6$ months of age was based upon the composition of breast milk and the normal average daily volume consumed $(780 \mathrm{~mL})$. The AI for children 7-12 months of age was obtained by adding the nutrient content of $600 \mathrm{~mL}$ of breastmilk to the estimated mean intake of solid food. ${ }^{30}$ There were a number of limitations in establishing an AI in these age ranges. For instance, dietary data from solid food was unavailable for many nutrients and had to be extrapolated from other age groups and the content of breast milk for some nutrients is unclear. Furthermore, nutrient intake should be thought of as a continuum from birth to 1 years and not an abrupt change in requirements at 6 months of age. ${ }^{30}$

It has long been recognized that the most rapid growth over the life course occurs in the first year of life. ${ }^{32}$ The energy needed for growth is estimated to be about $35 \%$ of the total energy requirement in the first month of life and gradually declines to less than $5 \%$ at 1 year of age. ${ }^{33}$ Lipids are the main source of energy during this time and are important for n-6 and n-3 polyunsaturated fatty acids. For example, arachidonic acid, eicosapentaenoic acid (EPA) and docosahexaenoic acid (DHA) are used for regulating growth, inflammatory responses, immune function and cognitive development. ${ }^{34}$ Lipids also support the absorption of lipid-soluble vitamins including vitamin A, vitamin D, vitamin E and vitamin K. Protein is another important 
source of energy and is also needed for provision of the nine essential amino acids which help with body maintenance and growth. Carbohydrates too are used as a source of energy with the main carbohydrate being lactose in breastmilk and infant formula. ${ }^{33}$

Micronutrients of importance during the first year of life include: Zinc, Calcium, Iodine, vitamin A, vitamin E, vitamin K, vitamin C, Iron, and vitamin D. ${ }^{33}$ Choline, Folate, vitamin B6 and vitamin B12 are also important for brain growth. ${ }^{18}$ Iron is of particular importance for growth, haematopoiesis, immune function and neurodevelopment. ${ }^{33}$ Healthy term infants are born with sufficient stores of iron due to placental iron transfer, but this is depleted in the first year of life because the iron content of breastmilk is low. ${ }^{33}$ Iron containing solid foods are needed by about 4-6 months of age to maintain healthy iron stores through the first year of life. ${ }^{33}$ Breastmilk also has a low vitamin D content and breastfed infants in Canada are recommended to supplement with $400 \mathrm{IU}$ of vitamin D from birth to 1 year of age. ${ }^{6}$ Similarly, infants are born with extremely low levels of vitamin K and the CPS and College of Family Physicians of Canada recommends a singular intramuscular injection of vitamin $\mathrm{K}$ to prevent vitamin $\mathrm{K}$ deficiency bleeding. ${ }^{35}$

Otherwise, the nutrient requirements of an infant can generally be met in the first 4-6 months of life through breast feeding or infant formula alone before solid foods need to be incorporated.

\subsection{Breast and formula feeding}

Breast or formula feeding is the first source of oral nutrition for infants. Breast milk is known to be the best source of nutrition for most infants. ${ }^{6,34}$ It is recommended in Canada to exclusively breastfeed until 6 months of age with continued breastfeeding for up to two years or more as desired by the mother and baby. ${ }^{6,36}$ The WHO defines exclusive breastfeeding as "an infant 
receives only breast milk from his or her mother or a wet nurse, or expressed breast milk, and no other liquid or solids, not even water, with the exception of oral rehydration solution, drops or syrups consisting of vitamins, minerals supplements or medicine". ${ }^{4}$ Terms such as non-exclusive breastfeeding, total breastfeeding and predominant breastfeeding suggests that a child may be consuming solids and liquids other than breastmilk or vitamins/minerals and medicines. Breast milk is composed of $87 \%$ water, $3.8 \%$ fat, $1 \%$ protein and $7 \%$ lactose; although, the content of breastmilk changes with the age of the child and the length of breastfeeding session. Breastmilk also contains vitamins, minerals, digestive enzymes, hormones and immune cells. Breast feeding is an inexpensive source of nutrition and promotes bonding between mother and infant.

Despite this, infant formula remains popular and is necessary when there are contraindications to breastfeeding. For instance, contraindications to breastfeeding noted by the CPS and American Academy of Pediatrics (AAP) include infants with glactosemia, maternal HIV positivity and mothers who are receiving cytotoxic chemotherapy. ${ }^{37,38}$ Low education, low income and other demographic characteristics have been shown to be predictors for lower breastfeeding initiation and duration of exclusivity. ${ }^{39}$ Infant formula is intended to mimic the content of breastmilk and is fortified with iron and vitamin $\mathrm{D}$ when designed to be a complete source of nutrition as seen in Table 1. Unfortunately, matching the content of breast milk is challenging. Some of the issues in mimicking breast milk include: the variability of breastmilk content over time and between mothers, breastmilk containing live components and bioactive components which cannot be added to formula or are not shelf stable and the ratio of nutrients added to formula influences their bioavailability. ${ }^{40}$ It is also difficult to test for formula's efficacy against breast feeding in randomized controlled trials (RCT) due to ethical limitations. 


\begin{tabular}{|c|c|c|}
\hline Nutrient & $\begin{array}{c}\text { Breast milk } \\
\text { (per 100mL) }\end{array}$ & $\begin{array}{c}\text { Infant formula }^{42} \text { a } \\
(\text { per 100mL) }\end{array}$ \\
\hline Energy (kcal) & 67 & 67 \\
\hline Protein $(\mathrm{g})$ & 1.3 & 1.5 \\
\hline Carbohydrate $(\mathrm{g})$ & 7.0 & 7.5 \\
\hline Fat $(\mathrm{g})$ & 4.2 & 3.4 \\
\hline Calcium $(\mathrm{mg})$ & 35 & 44 \\
\hline Vitamin D (IU) & 0.4 & 40 \\
\hline Iron (mg) & 0.1 & 1 \\
\hline
\end{tabular}

Table 1: Nutrition facts for breast milk and infant formula. ${ }^{a}$ Nestle Good Start Plus 1 baby formula, powder with standard dilution

Numerous studies have demonstrated the benefits of breastfeeding. During the first 6-8 weeks of life, there is little difference in growth between breast and formula fed infants. ${ }^{43}$ However, from 2 months to 1 year of age formula fed infants gain weight and length more rapidly and may not be as lean. ${ }^{43} \mathrm{~A}$ dose-response effect has been observed between duration of breastfeeding and decreased risk of obesity. ${ }^{44}$ A greater duration of exclusive breastfeeding or total breastfeeding has also been linked to less picky eating behaviour and greater diet variety later in childhood. ${ }^{45-47}$ Other benefits of breastfeeding could include fewer doctor's office visits and hospitalization, less frequent lower respiratory and gastrointestinal infections, and higher cognitive ability. ${ }^{48-50}$

\subsection{Growth Monitoring}

Growth measurements in early childhood are routinely conducted through primary healthcare visits and are important for monitoring health and identifying nutritional problems. ${ }^{51}$ Dietitians of Canada (DC), CPS, College of Family Physicians of Canada and the Community Health Nurses of Canada recommend that recumbent length (birth to 2 years) or standing height ( $\geq 2$ years) and weight measurements be done at all primary healthcare visits. ${ }^{51}$ Furthermore, 
measurements are recommended to be taken with calibrated, well-maintained equipment and standardized measurement techniques to ensure their accuracy. ${ }^{51}$

BMI is an indirect measure of adiposity and is calculated by dividing weight $(\mathrm{kg})$ by height squared $\left(\mathrm{m}^{2}\right)$. BMI is inexpensive, non-invasive, quick, requires minimal training and has established growth references. ${ }^{52}$ It has also been shown to be strongly correlated with body fat percentage and fat mass measured by Dual Energy X-Ray Absorptiometry (DEXA) which is considered the gold standard to define obesity. ${ }^{53,54}$ The main limitation to BMI is that it is an indirect measure of adiposity, meaning it measures excess weight, and not necessarily excess fat. ${ }^{55}$ Additionally, BMI does not provide information on the distribution of fat stores throughout the body which may be important to health in later life. ${ }^{55}$

There are several direct measures of adiposity available. DEXA measures bone mineral, bonefree lean mass and fat mass using x-ray beams. Although the level of radiation is low, it can accumulate with repeated measurements. ${ }^{52}$ Air displacement plethysmography (ADP) (commercially available as the "BOD POD" or "PEA POD") is able to determine the subject's density via pressure changes in a closed chamber and the subject's mass, and subsequently their body composition. Other direct measures of adiposity include magnetic resonance imaging (MRI), computed tomography (CT) and ultrasounds ${ }^{52}$ Direct measures of adiposity can be of value at the individual level, but their cost, time, and invasiveness make them impractical for routine collection in larger populations.

\subsection{Growth standards}


Growth references have been described as a statistical summary of anthropometry in a reference group of children. ${ }^{56}$ Growth references describe how children in a given population do grow. Growth standards are similar to growth references except the reference group of children are selected on health basis and represent how children ought to grow. ${ }^{56}$ The purpose of growth standards is to allow comparison of growth relative to a standard normal population. This allows healthcare providers and researchers to determine whether the child is growing as they should. DC, CPS, College of Family Physicians of Canada and the Community Health Nurses of Canada recommends during primary healthcare visits, all children be evaluated using the WHO growth standards from birth to 5 years, and WHO growth references from 5-19 years of age. ${ }^{51}$

The WHO growth standards for children 0-5 years were based on the 2006 multicentre growth reference study. ${ }^{57}$ This study included 8,500 children from Brazil, Ghana, India, Norway, Oman and the United States who were living in conditions favourable for growth. These children were selected from non-smoking households, with the absence of health problems, gestational age $\geq 37$ weeks and were predominantly breastfed. Longitudinal (0-24 months) and cross-sectional (18-71 months) analyses were conducted using Box-Cox-power-exponential (BCPE) distributions and smoothing cubic splines which allowed the creation of growth curves for children $0-5$ years. ${ }^{57}$ In 2007, the WHO constructed growth curves for children 5-19 years of age which aligned with the WHO child growth standards at 5 years and the recommended cut-offs for adult overweight and obesity at 19 years. ${ }^{58}$ A multicentre growth study was not feasible for this age group and a review of existing historical data sets were too heterogeneous to include. Thus, data from the 1977 National Center for Health Statistics (NCHS)/WHO growth reference (1-24 years) was reconstructed in the 5-19 year range and merged with data from the $2006 \mathrm{WHO}$ 
multicentre growth reference study to facilitate a smooth transition at 5 years. ${ }^{58}$ See Appendix A: WHO growth standards/reference (0-19 years BMI-for-age z-scores). WHO growth standards/reference are also available for length/height-for-age.

Unlike adults, children's optimal BMI and length/height vary by sex and age. ${ }^{59}$ Thus, BMI and length/height are often expressed as z-scores which adjust for child age and sex. This allows comparison of z-scores among children of different ages and sexes. The z-score is a measure of standard deviations (SD) relative to the WHO reference population. For example, a z-score of +1 indicates that the child is $1 \mathrm{SD}$ above the median measurement, and a SD of -1 indicates that the child is $1 \mathrm{SD}$ below the median measurement. A $\mathrm{z}$-score of 0 is the same as the median or $50^{\text {th }}$ percentile. Another benefit of z-scores is that they can be used to compare different measurements using the same (dimensionless) units. ${ }^{59}$ Cut-points been developed to classify children's growth relative to the WHO growth standard/reference. Table 2 describes the z-score cut-points. The cut-points for younger children are more conservative to avoid parents and health care professionals putting young children on diets. ${ }^{60}$

\begin{tabular}{|c|c|c|}
\hline \multirow{2}{*}{ Growth Status } & \multicolumn{2}{|c|}{ z-score } \\
\cline { 2 - 3 } & $0-5$ years & 5-19 years \\
\hline Risk of overweight & $>1$ & N/A \\
\hline Overweight & $>2$ & $>1$ \\
\hline Obesity & $>3$ & $>2$ \\
\hline Severe obesity & N/A & $>3$ \\
\hline
\end{tabular}

Table 2: BMI-for-age z-score and growth status based on WHO growth standard/reference ${ }^{60}$

In addition to the WHO growth standards, numerous other growth references are available. For instance, CDC's growth charts, which were last revised in 2000, describe how American children grow from birth to 20 years of age. ${ }^{61}$ The CDC recommends that clinicians in the US use the WHO growth standards for American children aged $<24$ months and the CDC growth charts for 
children $\geq 24$ months. ${ }^{62}$ Similarly, the Euro-Growth reference, released in 2000, describe the growth of European children from birth to 3 years of age.$^{63}$ ESPGHAN recommends that the WHO growth standards be used for European children $<24$ months and be considered for use in children $\geq 24$ months. $^{64}$

\subsection{Childhood obesity in Canada}

According to the Canadian Community Health Survey (CCHS), 63\% of Canadian adults were overweight or obese in $2018 .{ }^{65}$ This was similar to 2015 when $62 \%$ of Canadian adults were overweight or obese. ${ }^{65}$ The CCHS is a cross-sectional survey that collects information related to the health status, health care utilization and health determinants of the Canadian population. The Public Health Agency of Canada estimated the average annual direct health care costs to be higher for obese $(\$ 2,283)$ and overweight $(\$ 1,726)$ individuals than those at normal weight $(\$ 1,298)$. It is projected that obesity among Canadian adults will continue to rise over the next decade. ${ }^{66}$ On the other hand, in 2012/2013 about $31 \%$ of Canadian children were overweight or obese (defined as BMI z-scores using the WHO growth reference $>1$ and $>2$, respectively) ${ }^{67}$ This number has remained consistent since 2004, but the prevalence remains high. ${ }^{67}$

International overweight and obesity trends appear to mimic those in Canada. Adult mean BMI continues to rise in all regions of the world. ${ }^{68}$ In children, obesity has increased gradually over the last 4 decades, but there recently has been some flattening trends in parts of Europe and in other high-income countries. ${ }^{68}$ The global age standardized mean BMI in children and adolescents was about $17.0 \mathrm{~kg} / \mathrm{m}^{2}$ in 1975 and in 2016 it was $18.5 \mathrm{~kg} / \mathrm{m}^{2} .68$ 


\subsection{Determinants of height}

Height is influenced by genetic and environmental factors. ${ }^{69}$ In fact, height has been shown to be one of the most heritable human phenotypes. ${ }^{69}$ About $80 \%$ of height differences are due to genetic variation in western societies (and possibly less in poorer countries). ${ }^{70}$ For example, maternal height has been shown to be a good predictor of offspring growth from birth through adulthood. ${ }^{71}$ However, height has increased greatly over the last century which cannot be explained by genetic factors alone.

The greatest influence of nutrition on height occurs during infancy. ${ }^{69}$ Two important environmental determinants of height are disease and nutrition. Disease can hinder food intake and nutrient absorption and inadequate nutrition can increase the likelihood of infections. ${ }^{25}$ For instance, individuals in Switzerland with earlier onset of Crohn's disease achieved a lower final height. ${ }^{72}$ Hwang et al. conducted a study of monozygotic twins born in California, US, and followed them into adulthood. ${ }^{73}$ It was found that the twin with more episodes of toddler infection was about three times as likely to be the shorter twin. ${ }^{73}$ Differences in nutrient consumptions may also play a role in height. Grasgruber et al. showed the most important factor explaining the differences in height among 45 European nations was nutrition, specifically the ratio between intake of high quality proteins (e.g. milk products, animal products) and low quality proteins (e.g. wheat). ${ }^{74}$ Adequate mineral, vitamin A, and vitamin $\mathrm{D}$ consumption could also affect linear growth. ${ }^{25}$

Section 2: Introduction to solid food in children

\subsection{Physiological readiness for solid foods}


A fetus and young infant are entirely reliant on their mother for nutrition through the umbilical cord and breastmilk. After birth, an infant begins maturation so they can become independent from maternal resources. ${ }^{75}$ At birth, a full-term infant's gastrointestinal tract is anatomically and functionally mature ${ }^{75}$ By 4 months of age, an infant should be able to metabolize nutrients from solid foods and the ingestion of solid foods may drive further maturation. ${ }^{5}$

Children also require the oro-motor skills to safely consume solid foods. Full-term babies are born with several reflexes including swallowing, sucking, gag, phasic bite (i.e. rhythmic opening and closing of jaw) and rooting. ${ }^{75}$ Children can safely consume pureed food from a spoon at about the 4-6 month range. ${ }^{5}$ As the strength of the tongue and stability of the trunk and neck develops, children can safely consume semi-solid food at about 6 months of age., ${ }^{5,75}$. Health

Canada, CPS, DC and the Breastfeeding Committee for Canada recommendations note the signs of physiological and developmental readiness for solid foods as: better head control, ability to sit up and lean forward, ability to let the caregiver know when they are full and the ability to pick up food and try to put it in their mouth. ${ }^{6}$

\subsection{WHO and international guidelines}

The WHO provides guidelines for when solid foods should be introduced. In 1995, the WHO recommended that infants be exclusively breastfed for 4-6 months and then introduced to nutritionally adequate and safe complementary foods. ${ }^{76,77}$ In 2001, the WHO updated their guidelines to recommend 6 months of exclusive breastfeeding followed by the introduction of solids foods. ${ }^{78}$ The change in the guideline was based upon a systematic review in 2000 which compared children who were exclusively breastfed for 3-4 months and then introduced to solid 
foods with continued breastfeeding to 6 months vs. those exclusively breastfed for 6 months. A total of 16 studies were included in the review, 7 from developing countries (two of which were controlled trials in Honduras) and 9 from developed countries (all observational). One of the main findings was that exclusive breastfeeding for 6 months and then the introduction of solid foods resulted in a reduction of gastrointestinal infection based on an observational anaylsis of a large randomized trial in Belarus $(\mathrm{n}=3483) \cdot{ }^{79,80} \mathrm{In} 2012$, the WHO conducted a similar systematic review and the recommendation to exclusively breastfeed for 6 months and then introduce solid foods was reaffirmed. ${ }^{81}$ This systematic review included a total of 23 studies, 11 studies from developing countries (two of which were the same controlled trials from the previous review conducted in Honduras) and 12 from developed countries (all observational). The main finding was again a reduction in gastrointestinal illness for those exclusively breastfed for 6 months. ${ }^{81}$ In addition to the study conducted in Belarus, two prospective cohort studies conducted in Iran $(\mathrm{n}=193)$ and Nigeria $(\mathrm{n}=309)$ also found a reduction in the risk of gastrointestinal and respiratory infection with exclusive breastfeeding to 6 months. ${ }^{82,83}$ However, the authors of these studies noted that unhygienic food preperation likely explained why those started on solid foods earlier had worse outcomes which may not be applicable globally. In 2020, the WHO began the process of conducting another systematic review to revaluate if the introduction of solids foods at 6 months, compared to earlier or later, is beneficial. ${ }^{84}$

Not all policy making organizations have the same recommendations for introducing solid foods as the WHO. Table 3 shows current guidelines for when to introduce solid food around the world. 


\begin{tabular}{|c|c|}
\hline Organization & $\begin{array}{l}\text { Recommendation for when to } \\
\text { start solids foods }\end{array}$ \\
\hline $\begin{array}{l}\text { American Academy of Pediatrics } \\
(\text { (AAP) })^{7}\end{array}$ & $\approx 6 \mathrm{mo}$ \\
\hline $\begin{array}{c}\text { European Society for } \\
\text { Gastroenterology, Hepatology and } \\
\text { Nutrition (ESPGHAN) }\end{array}$ & 4-6 mo \\
\hline Australian Department of Health ${ }^{85}$ & $\approx 6 \mathrm{mo}$ \\
\hline Netherlands Youth Health Centre ${ }^{10}$ & $\begin{array}{c}4-6 \text { mo } \\
\text { (small snacks at } 4 \text { mo) }\end{array}$ \\
\hline Swedish National Food Agency ${ }^{9}$ & $\begin{array}{l}6 \text { mo } \\
\text { ("tiny tastes" can start at } 4 \text { mo) }\end{array}$ \\
\hline
\end{tabular}

Table 3: International guidelines for when to introduce solid foods

\subsection{Canadian guidelines}

Canadian guidelines on the introduction of solid foods have evolved over the years to match WHO guidelines. In 1998, Canada recommended introduction of "complementary foods at four to six months to meet the infant's increasing nutritional requirements and developmental needs." ${ }^{" 86}$ Iron-containing foods, such as iron-fortified cereals, were recommended as first solid foods. ${ }^{86}$ In 2005, Canada updated their guidelines to recommend the introduction of solid food at 6 months, following 6 months of exclusive breastfeeding. ${ }^{87}$ Canada's guidelines were last modified in 2012. ${ }^{6,88}$ These current guidelines set out by Health Canada, CPS, DC and the Breastfeeding Committee for Canada recommend exclusive breastfeeding for 6 months and then the introduction of solid foods. First solid foods are recommended to be iron- rich; such as, meat, meat alternatives and iron-fortified infant cereal. ${ }^{6,88}$

\section{Introduction to solid food vs. complementary feeding}

The terms timing of introduction to solid foods and timing of complementary feeding are often used interchangeably. The CPS's recommendation of first complementary foods being iron-rich 
would be the same as a recommendation for the first solid foods being iron rich. Similarly, ESPGHAN defines complementary feeding to include all solid and liquid foods other than breastmilk or infant formula. ${ }^{5}$

\subsection{Timing of introduction to solid food in children}

Most international guidelines recommend introducing solid foods in the 4-6 mo range. Yet, these guidelines are seldom met. In 2007, Haiek et al. conducted a cross-sectional survey of 632 mother/infant pairs from Quebec when the infant was 6 months of age and found that $70 \%$ of infants had received solid food by 4 mo. ${ }^{89}$ Data from the 2012 CCHS showed that $11 \%$ of Canadian infants consumed solid foods by $\leq 3$ mo and $32 \%$ at $4-5$ mo. ${ }^{90}$ Clayton et al. conducted a longitudinal study in 2013 of 1334 mothers distributed throughout the United States and found that $40 \%$ of mothers introduced solid food by $\leq 3$ mo. ${ }^{91}$ In 2010 , Schiess et al. evaluated data collected in 5 European countries as part of the European Childhood Obesity Project ( $\mathrm{n}=1678)$ and found that $37 \%$ of formula fed infants and $17 \%$ of breastfed infant were introduced to solid food by $\leq 4$ mo. ${ }^{92}$

Several studies have identified predictors for the timing of introduction to solid food. The 2012 CCHS identified that Canadian mothers who exclusively breastfed their child longer, and thus introduced them to solid foods later, tended to be older and have a higher degree of education. ${ }^{90}$ Some reasons mothers provided for introducing solid food before recommended included: my "baby was ready for solids"; "not enough breastmilk"; "my baby was old enough"; "my baby seemed hungry"; and, "a healthcare professional said by baby should begin eating solid food." ${ }^{90,91}$ Formula fed children tend to be introduced to solid food earlier than breastfed 
children. ${ }^{91,92}$ Health care professionals not following nutrition guidelines could also play a role in caregivers introducing solid food before recommended. Samady et al. conducted a survey study in 2020 among American practitioners ( $n=563,80 \%$ pediatricians) to evaluate the age at which they recommended to introduce solid foods..$^{93} 48 \%$ of respondents recommended introducing solid foods at 6 months among exclusively breastfed children, and 34\% recommended 6 months for non-exclusively breastfed children. ${ }^{93}$ In other words, less than half of respondents suggested introducing solid food at the recommended age. Other factors which may predictor earlier introduction to solid foods include gender, gestational age, birth weight and maternal BMI. ${ }^{94}$

\subsection{The first solid food trends}

Which solids are introduced first varies internationally. Health Canada, CPS, DC and the Breastfeeding Committee for Canada specifically recommend that first solid foods be iron-rich, such as iron-fortified infant cereal, meat, and meat alternatives. ${ }^{6}$ Other countries such as Sweden (Swedish National Food Agency), the United States (American Academy of Pediatrics), and United Kingdom (UK National Health Service) do not recommend specific foods to be started first. $^{7-9}$

In 2010, Friel et al. conducted a nationally representative cross-sectional survey of Canadian children 3-12 months of age $(n=2663)$ which included a 4-day dietary record and found that infant cereal was consumed by the greatest proportion of children early in life. ${ }^{95}$ The proportion of children consuming infant cereal was $83 \%, 83 \%$ and $89 \%$ at 3,4 and 5 months of age, respectively. At 6 months, $81 \%$ of children were consuming infant cereal which was second to only vegetables at $88 \% .{ }^{95}$ The 2016 Feeding Infants and Toddlers Study (FITS) was a cross- 
sectional survey using 24-hour dietary recalls. ${ }^{96}$ It included a random sample of American caregivers of children $<4$ years $(n=3235)$ and showed similar results to Friel et al. ${ }^{96}$ Infant cereal was the most commonly consumed food from $0-3.9 \mathrm{mo}$ and $4-5.9 \mathrm{mo}$. Infant cereal was consumed by $13 \%, 54 \%$ and $84 \%$ of infants $0-3.9 \mathrm{mo}, 4-5.9 \mathrm{mo}$ and $6-11.9 \mathrm{mo}$, respectively. ${ }^{96}$ Other international cohorts have also shown infant cereal to be among the first solid foods introduced. ${ }^{97,98}$

\subsection{Infant cereal nutritional content}

Infant cereal is recommended as a first solid food. There are several characteristics of infant cereal which make it a desirable first solid food. First, infant cereal is a good source of many vitamins and minerals, fibre and bioactive compounds. ${ }^{99}$ Non-digestible carbohydrates found in infant cereal can help colonize the microbiome. Infant cereal is fortified with iron which is important at a time when infant stores are depleted, although it can be sourced without iron. ${ }^{99} \mathrm{~A}$ recent American study using National Health and Nutrition Examination Survey (NHANES) data $(n=5587)$ found that infants who consumed infant cereal compared to those who did not had higher intakes of carbohydrate, iron, calcium, magnesium, zinc and vitamin E. ${ }^{100}$ Second, infant cereal has a mild taste and semi-solid consistency which may help with its acceptance. It can also be mixed with breastmilk or infant formula to increase its familiarity. ${ }^{99}$

\subsection{Caregiver feeding approaches}

There are two main approaches to introducing solid foods: traditional or baby-led weaning (BLW). Traditionally, infants are spoon fed pureed foods and then gradually the caregiver advances the texture. In the BLW approach, infants feed themselves small, soft finger foods from 
the start of the introduction to solid foods. ${ }^{101}$ BLW is hypothesized to lower obesity risk by improving energy self-regulation. ${ }^{101,102}$ Taylor et al. conducted a RCT in Dunedin, New Zealand $(n=206)$ which randomized children to follow a BLW or traditional approach to introducing solid food. There was no evidence of a difference in BMI z-score between the groups at 12 months or 24 months. Although, parents of children in the BLW group reported less food fussiness. ${ }^{102}$ Overall, BLW has gained popularity only recently and further studies are needed to understand its impact. ${ }^{103}$

In addition to the traditional and BLW approaches to initiate solid foods, caregivers also incorporate a wide variety of strategies while feeding their children or attempting to facilitate feeding. Feeding practices are the approaches and behaviours caregivers take to feed their children. ${ }^{104}$ Feeding practices are complex behaviours which can change overtime and it is not easy to categorize them. Spill et al. conducted a systematic review ( $n=27$ studies) to evaluate the relationship between caregiver feeding practices from birth to 24 months and growth. The authors concluded that mother's responding appropriately to their child's hunger and satiety cues can lead to normal weight status. Conversely, restrictive feeding practices were associated with increased weight gain. ${ }^{104}$

Section 3: Role of timing of introduction to solid food on growth and nutrition risk

\subsection{Adiposity}

Reviews 
Systematic reviews on the timing of introduction to solid food and growth have shown inconsistent results. In 2013, Pearce et al. conducted a systematic review (21 observational studies) on the timing of introduction to solid food and childhood obesity and found no clear association but did note that very early introduction (i.e. $\leq 4 \mathrm{mo}$ ) may increase the risk of childhood overweight. ${ }^{105}$ In 2011, Moorcroft et al. conducted a systematic review (1 RCT, 23 observational studies) on the relationship between the timing of introduction to solid food and obesity and did not find evidence of an association. ${ }^{106}$ Most recently, in 2019, English et al. conducted a systemic review ( 2 RCTs, 79 observational studies) on the timing of introduction to complementary foods and growth and found moderate evidence that introduction between 4 and 6 months was not associated with differences in growth. ${ }^{14}$ There was limited evidence that introduction $\leq 3$ months was associated with higher odds of obesity and insufficient evidence to draw any conclusions regarding those introduced to complementary foods $\geq 7$ months. Although, English et al. noted a number of limitations in the reviewed studies including: not accounting for key confounding variables, use of self-reported weight/height, and few comparisons between children introduced to solid food in the 4 to 6 month range. ${ }^{14}$

\section{Observational}

Most of the evidence on the relationship between the timing of introduction to solid food and adiposity comes from observational work. Sun et al. conducted a cross-sectional study in Melbourne, Australia ( $\mathrm{n}=3153$ ) and found that children introduced to solid food $\leq 4$ months or $\geq 7$ months, compared to 5 to 6 months, had higher odds of above normal BMI (i.e. body mass index z-score $(z B M I)>2$ ) at 1 year of age. ${ }^{12}$ Zheng et al. conducted a prospective cohort study in Southeast China $(\mathrm{n}=43,848)$ and found that children introduced to complementary food $\leq 3$ 
months or $\geq 7$ months, compared to 4 to 6 months, had greater zBMI and risk of overweight at 45 years of age. ${ }^{107}$ These findings suggest that a non-linear relationship between time introduced to solid food and growth may exist. Seach et al. conducted a cohort study in Melbourne, Australia $(n=307)$ and found that delayed introduced of solid food was associated with a reduced risk of being overweight or obese at 10 years of age. ${ }^{108}$ This was one of the only study's to measure time introduced to solid food continuously and test for non-linearity; however, evidence for including non-linearity was not found. ${ }^{108}$

\section{Randomized Controlled Trials}

Due to ethical and practical limitations, few RCTs have been conducted in this area. In fact, of the 81 studies included in the review by English et al., only 2 were RCTs from developed countries. ${ }^{14}$ Bainbridge et al. conducted a RCT in Cincinnati, United States $(n=41)$ among formula fed children. ${ }^{109}$ Children were randomized to either exclusively formula feed for the first 6 months of life (formula group) or exclusively formula feed for 4 months with introduction to cereal at 4 months and continued formula feeding until 6 months (cereal group). There was no evidence of a difference in anthropometric measurements between the formula group and cereal group at 6 months (26 weeks). ${ }^{109}$ Although, Bainbridge et al. noted that the sample size may not have been sufficient to detect a difference between groups. ${ }^{109}$ Jonsdottir et al. conducted a RCT in Iceland ( $n=119)$ among breastfed children. Children were randomized to either exclusively breast feed for the first 6 months of life (breastfed group) or exclusively breast feed for 4 months with introduction to solid foods at 4 month and continued breast feeding until 6 months (solid

food group). ${ }^{110}$ There was no evidence of a difference in growth rate between 4 and 6 months of age in the breastfed group vs. solid food group. ${ }^{110}$ These children were followed-up at 28-39 
months of age and there were still no differences in weight or BMI between the breastfed group and solid food group. ${ }^{111}$ Two additional RCTs were completed in Honduras in the 1990s. These studies were conducted among low income subjects, under poor sanitary conditions and among

low birth weight infants in one of the RCTs so the generalizability of their results is limited. ${ }^{112,113}$ Nevertheless, there was little evidence of a difference in weight or length for those started on solid foods at 4 vs. 6 month of age following a period of exclusive breastfeeding. ${ }^{112,113}$

\subsection{Height}

Reviews

The existing literature examining the relationship between time introduced to solid food and height is scarce compared to adiposity and generally does not show evidence of an association. The aforementioned systematic review by English et al. included 28 studies which examined the relationship between time introduced to solid food and length/height. There was moderate evidence that time introduced to infant cereal in the 4 to 6 month range was not associated with height and insufficient evidence was available to draw conclusions for those introduced to solid food $\geq 7$ months.

\section{Observational}

Moschonis et al. conducted a study using data from 4 European cohorts $(n=309-7540)$ and found that timing of complementary feeding was not consistently associated with height between 4 and 13 years of age. ${ }^{114}$ Similarly, Zhu et al. conducted a cross-sectional study in the United States $(n=1387)$ and did not find timing of introduction to solid food to be associated with height 
through 6 years of age. Interestingly, an association was found between later introduction of solid food and greater ulnar length. ${ }^{107}$

\section{Randomized Controlled Trials}

The RCT by Bainbridge et al. discussed previously found that children introduced to cereal at 4 months had a greater increase in length between 4 and 6 months compared to those exclusively formula fed through the first 6 months of life. ${ }^{109}$ However, no significant difference in length was detected at 6 months of age (26 weeks) between the two groups. ${ }^{109}$ Meanwhile, Jonsdottir et al. did not find a difference in length/height through 29-38 months of age in children exclusively breastfed for 6 months vs. those excessively breastfed for 4 months and then started on solid foods. ${ }^{111}$

See Appendix B: Summary of previous studies evaluating the relationship between the timing of introduction to solid food and growth.

\subsection{Nutrition risk}

The American Dietetic Association defines nutrition risk as the presence of characteristics or risk factors that lead to impaired nutritional status. ${ }^{115}$ Nutritional risk factors include items such as consuming few meals/snacks, low fruit and vegetable consumptions, delayed acquisition of feeding skills and food intolerances. The available evidence suggests that the timing of introduction to solid food may be a risk factor for nutrition risk. However, the literature on this topic is heterogenous and the direction of the relationship is inconsistent. 
Northstone et al. conducted a longitudinal study in Avon, England ( $\mathrm{n}=9360)$ and found that children who were introduced to "lumpy" solids $<6$ months, compared to 6-9 months, were consuming a greater variety of foods at 6 months of age. ${ }^{116}$ On the other hand, children introduced to lumpy solids at $\geq 10$ months, compared to 6-9 months, consumed less variety of solid foods and were more difficult to feed at 6 and 15 months of age. ${ }^{116}$ Coulthard et al. followed up with this cohort at 7 years of age $(n=7821)$ and found that the children introduced to "lumpy" solids $\geq 10$ months were still having more feeding problems and were consuming less fruits and vegetables. ${ }^{117}$ It is noteworthy that these studies were examining specifically timing of introduction to "lumpy" solids and the generalizability to the timing of introduction of any solids isn't clear. Children introduced to "lumpy solids" $\geq 10$ months also consumed significantly less baby cereal at 6 months of age compared to those introduced to "lumpy solids" $<6$ months or 6-9 months which may suggest they were also introduced to any solid foods at a later age.

Conversely, Hollis et al. conducted a prospective cohort study in Southampton, United Kingdom $(n=2389)$ and found that children who were introduced to solid food $\geq 6$ months had a lower risk

of feeding difficulties compared to those introduced at 4-5 months at 3 years of age. ${ }^{118}$ Abraham et al. conducted a longitudinal birth cohort study $(n=5217)$ in Scotland and found that children who started complementary feeding at 4-5 months or 6-10 months, compared with 0-3 months, had a more positive eating pattern at 2 years of age. ${ }^{13}$ See Appendix C: Summary of previous studies evaluating the relationship between the timing of introduction to solid food and nutrition risk.

\subsection{Hypothesized mechanisms}


Although the exact mechanism explaining the relationship between the timing of introduction to solid food and growth and nutrition risk is uncertain, several hypotheses have been proposed. It has been suggested that calorie and protein intake, reverse causality and a sensitive period of development may all help to explain the relationship between the timing of introduction to solid food and growth and nutrition risk.

\section{Energy and Protein Intake}

It is possible that the introduction to solid foods increases total energy intake which is why children introduced to solid food earlier exhibit more rapid growth. However, this hypothesis has not been supported. Mehta et al. conducted a RCT in Cincinnati, United States $(\mathrm{n}=165)$ which randomized children to receive either: (1) commercial solid foods from 3-12 months, (2) commercial solid foods from 6-12 months, (3) parents' choice of solid foods from 3-12 months, or (4) parents' choice of solid foods from 6-12 months. ${ }^{119}$ Total energy intake was not different in any of the groups from 3 months through to 12 months of age. ${ }^{119}$ Similarly, Cohen et al. conducted a RCT in San Pedro Sula, Honduras $(\mathrm{n}=141)$ which randomized children who were exclusively breastfed for 4 months to either: (1) exclusively breastfeed until 6 months, (2) introduce solid foods with ad lib breastfeeding until 6 months, or (3) introduce solid foods with continued baseline frequency of breastfeeding until 6 months. ${ }^{112}$ There was not a significant difference in caloric intake between any of the groups at 6 months of age. ${ }^{112}$ As was previously mentioned, this study was conducted among low income subjects and under poor sanitary conditions so the generalizability of results to developed countries may be limited. 
It has also been hypothesized differences in nutrient intake, specifically protein, contributes to the changes in growth. A high protein intake may increase insulin-like growth factor-1 (IGF1). ${ }^{120}$ IGF-1 can stimulate protein synthesis and cell proliferation, and may induce hyperplasia in adipose tissue. Simultaneously, a high protein intake may decrease growth hormone (GH) levels which leads to decreased lipolysis and the maintenance of high fat stores. ${ }^{120}$ Hornell et al. conducted a systematic review ( $\mathrm{n}=37$ studies) on the health effects of protein intake levels in infancy and childhood. ${ }^{121}$ It was found that high protein intake in infancy was associated with higher BMI in childhood, and the first 2 years of life were the most sensitive to high protein intake. ${ }^{121}$ The previously described RCT by Mehta et al. did not find differences in protein intake between 3 and 6 months of age for children introduced to solid food at 3 months vs. 6 months. ${ }^{119}$ Conversely, Heinig et al. conducted a cohort study in the United States $(n=105)$ which showed breastfed infants introduced to solid food between 4-6 months, compared to those introduced $>6$, had a greater protein intake at 6 and 9 months of age. ${ }^{122}$ This is likely due to the higher protein density in solid foods than in breast milk and infant formula as shown in Table 4.

\begin{tabular}{|l|c|}
\hline \multicolumn{1}{|c|}{ Food } & g protein $/ 100 \mathrm{~g}$ \\
\hline Ground Beef & 14 \\
\hline Infant cereal $^{\mathrm{a}}$ & 14 \\
\hline Egg & 13 \\
\hline Avocado & 2 \\
\hline Sweet potato & 1.6 \\
\hline Infant formula $^{\mathrm{b}, \mathrm{c}}$ & 1.5 \\
\hline Breastmilk $^{\mathrm{b}}$ & 1.3 \\
\hline
\end{tabular}

Table 4: Protein content of breast milk, infant formula, and common first solid foods ${ }^{\mathrm{a}}$ Gerber rice cereal. Diluted with water to approximately $4 \mathrm{~g}$ protein $/ 100 \mathrm{~g}$ ${ }^{b}$ Density assumed to be $1 \mathrm{~g} / \mathrm{ml}$. However, it is reported to be approximately $1.03 \mathrm{~g} / \mathrm{ml} .{ }^{123}$ ${ }^{\mathrm{c}}$ Nestle Good Start Plus 1 baby formula, powder with standard dilution 
Reverse causality is the concept that an exposure and outcome are related, but not in the direction that was expected. In this case, it is expected that the timing of introduction to solid food (the exposure) causes a change in growth (the outcome). Reverse causality would suggest that differences in growth result in caregivers introducing solid food at different times. Evidence for reverse causality is inconsistent.

Van Rossem et al. conducted a birth cohort study in the Netherlands $(n=3184)$ and examined differences in weight-for-height before and after the introduction of solids foods. ${ }^{124}$ It was found that children introduced to solid foods at 3-6 months had a greater weight-for-height before the introduction of solid foods than those introduced at 0-3 months or $>6$ months. ${ }^{124}$ Huh et al. conducted a prospective cohort study in Massachusetts, United States $(n=847)$ and found that the timing of introduction to solid food and subsequent growth was independent of weight-for-age zscore from 0 to 4 months of age. ${ }^{125}$ Lastly, the cohort study previously described by Heinig et al. showed breastfed infants introduced to solid food between 4-6 months had a lower growth velocity (grams/month) from 0-4 months of age than those introduced to solid food $>6$ months. ${ }^{122}$ Evidently, further research on this topic is warranted.

\section{Sensitive Period of Development}

The aforementioned hypotheses may help to explain why earlier introduction to solid food leads to a higher risk of overweight and obesity. However, the literature has shown that both early and late introduction to solid food could result in greater risk of overweight and obesity. A sensitive period of development could help explain this ' $U$ ' shaped relationship. A sensitive period of development is one in which it is easier for learning to take place. ${ }^{126} \mathrm{~A}$ behaviour can still be 
learned outside of a sensitive period, but with more resistance. ${ }^{126}$ Illingworth first proposed this idea saying that children should be given solids to chew at a time when they are developmentally ready; if they are not given solids then, they are likely to have difficulty taking them later. ${ }^{127}$ Several studies described in the nutrition risk section highlighted the relationship between timing of introduction to solid foods and feeding difficulties and patterns later in childhood. ${ }^{13,116-118}$ Furthermore, numerous studies have demonstrated that early introduction of fruits and vegetables was associated with higher vegetable intake in later childhood. ${ }^{97,128,129}$

There is also a stage in development characterized by extreme refusal of new foods called the neophobic stage. ${ }^{130}$ This stages peaks at approximately 20 months of age and fades by 5 to 8 years of age. ${ }^{130}$ Blisset et al. conducted a correlation analysis in the UK among 25 children 2-4 years of age and their caregivers. ${ }^{131}$ Caregivers and their children consumed a lunch which included several novel foods to the children while being observed. It was found that children introduced to solid foods earlier in life were more likely to consume the novel foods. ${ }^{131}$ However, introducing solid foods too early can also be problematic. Children introduced to some foods too early try to consume them with a "liquid swallow" which lands on the back of the tongue and produces and aversive gag reflex. ${ }^{126}$

It is possible that nutrition risk is mediating the relationship between time introduced to solid food and growth as seen in Figure 1. Liberali et al. conducted a systematic review on the relationship between dietary patterns in childhood and obesity risk (16 studies). ${ }^{132}$ Dietary patterns were categorized as either: (1) including potentially obesogenic foods or, (2) including 
mostly foods considered healthy. The authors concluded that diets including mostly healthy foods would be effective at reducing the risk of obesity. ${ }^{132}$

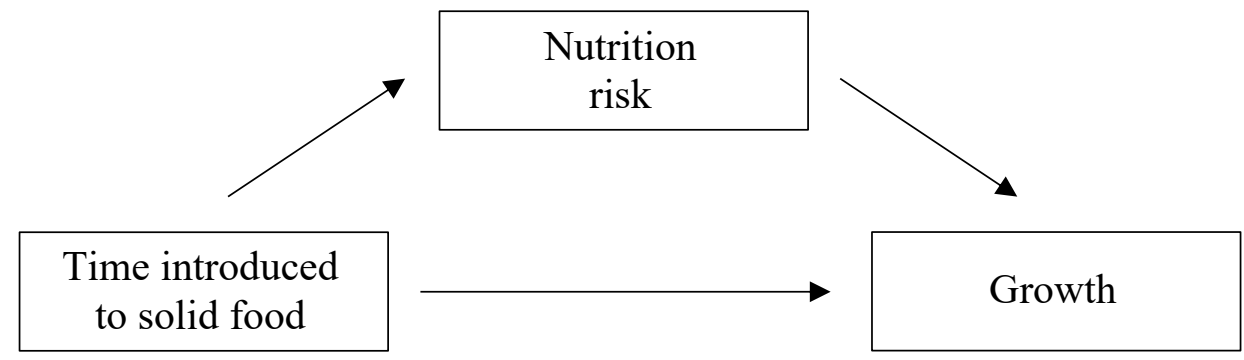

Figure 1: Nutrition risk mediating the relationship between timing of introduction to solid food and growth

\section{$\underline{\text { Section 4: Summary of literature review }}$}

Nutrition during childhood can have a profound impact on growth and nutrition risk. Early in life is when solid foods are first introduced into the diet and is necessary for nutrient provision and development. Deciding when to introduce solid foods has important health implications and is a decision all caregivers must make. Yet, international recommendations vary as to when solid foods should be first introduced to the diet in the 4 to 6 month range. Canada and the WHO recommend solid foods be introduced at 6 months of age. ESPGHAN recommends solid foods be introduced between 4 and 6 months of age.

Current evidence suggests that children introduced to solid food outside of the 4 to 6 month range may be at greater risk of overweight and obesity and at greater nutrition risk. However, little is known about children introduced to solid food within the 4 to 6 month range and how their growth and nutrition risk differs. It is important to understand these difference because it has the potential to improve health outcomes for Canadian children and children around the world. 


\section{CHAPTER 3: TIMING OF INTRODUCTION TO SOLID FOOD, GROWTH AND NUTRITION RISK IN LATER CHILDHOOD}

\subsection{Abstract}

Importance: Global nutrition recommendations differ on when solid foods are recommended to be introduced in the 4 to 6 month range. Few studies have differentiated between the 4 to 6 month period.

Objective: To evaluate the relationship between timing of introduction to infant cereal as the first solid food between 4 and 6 months and growth and nutrition risk.

Design: A longitudinal cohort study was conducted among children participating in The Applied Research Group for Kids (TARGet Kids!) cohort study between June 2008 and August 2019.

Setting: TARGet Kids! is a primary care practice-based research network in Toronto, Canada.

Participants: Healthy children 0 to 10 years of age.

Exposure: Parent report of the timing of introduction to infant cereal.

Main Outcomes(s) and Measures(s): The primary outcome was Body Mass Index z-score (zBMI). Secondary outcomes were weight status categories, height-for-age z-score (zHeight), nutritional risk measured using the Nutrition Screening Tool for Toddlers and Preschoolers (NutriSTEP) questionnaire and NutriSTEP sub-scores for dietary intake and eating behaviour. Linear mixed effect modelling was used to evaluate the association between the timing of 
introduction to infant cereal and zBMI, zHeight and nutrition risk. Generalized estimating equation modelling was used to explore weight status categories. Effect modification by child age and breast/formula feeding were explored.

Results: A total of 8943 children were included. Mean age of introduction to infant cereal was 5.7 months. In the primary analysis, children who were introduced to infant cereal at 4 vs. 6 months had 0.17 higher zBMI $(95 \%$ CI: $0.06,0.28 ; P=0.002)$ and higher odds of obesity (OR $1.82 ; 95 \%$ CI: $1.18,2.80 ; P=0.006)$ at 10 years of age. In the secondary analysis, children who were introduced to infant cereal at 4 vs. 6 months had 0.09 higher zHeight (95\% CI: 0.04, 0.15; $P=0.002$ ) at 1 year of age, which was not observed at 5 or 10 years of age, and worse NutriSTEP eating behaviour sub-score at 18 months to 5 years of age ( 0.18 units higher; $95 \% \mathrm{CI}$ : $0.07,0.29$; $P=0.001)$.

Conclusions and Relevance: Introduction of infant cereal at 4 vs. 6 months was associated with higher zBMI, higher odds of obesity, similar zHeight and worse eating behaviour. These findings support recommendations for introducing solid food around 6 months of age.

\subsection{Introduction}

The timing of introduction to solid food may be an important modifiable factor for improving child growth and nutritional risk. ${ }^{133,134}$ Around 4 to 6 months of age, breast milk or infant formula alone are no longer adequate to meet an infant's energy and nutrient requirements and solid foods are recommended to be initiated. ${ }^{4}$ Since 2005 , Canada has recommended introducing solid foods at 6 months of age and explicitly mentions iron-fortified infant cereal as a good first 
option. ${ }^{6,87,135}$ The AAP and World Health Organization (WHO) also recommend that solid food be introduced around 6 months of age. ${ }^{4,136}$ Yet, a survey conducted in 2019 of mainly American pediatricians $(n=563)$ found that less than half recommend introducing solid food at 6 months. ${ }^{93}$ ESPGHAN recommends that solid food be introduced between 4 and 6 months of age. ${ }^{5}$

Nutritional risk can be defined as the presence of risk factors leading to impaired nutritional status. ${ }^{15}$ Several studies have identified that introduction to solid foods $<4$ months or $>6$ months is associated with a higher body mass index (BMI). ${ }^{11,12,105,107,125}$ However, it is unclear whether introduction of solid foods between 4 and 6 months of age is associated with differences in growth or nutritional risk. A better understand may help improve children's growth and nutritional status.

The primary objective of this study was to evaluate the relationship between the timing of introduction to infant cereal as the first solid food between 4 and 6 months of age and body mass index z-score (zBMI) among healthy children from birth to 10 years of age. The secondary objectives were to examine the relationship between the timing of introduction to infant cereal between 4 and 6 months of age and: length/height-for-age z-score (zHeight), nutrition risk measured using the Nutrition Screening Tool for Toddlers and Preschoolers (NutriSTEP) and NutriSTEP sub-scores for dietary intake and eating behaviour. We also explored whether these relationships were modified by child age and/or by breast or infant formula feeding in the first year of life. 
We hypothesized that introduction to infant cereal at 4 months compared to 6 months would be associated with a higher zBMI and worse NutriSTEP scores and may also negatively impact height in later childhood.

\subsection{Methods}

Study Design and Participants

A longitudinal cohort study was conducted using repeated measures from birth to 10 years of age among children who participated in The Applied Research Group for Kids (TARGet Kids!) cohort study between June 2008 and August 2019. TARGet Kids! is a primary care, practicebased research network in Toronto, Canada (www.targetkids.ca). ${ }^{137}$ Data were collected at primary healthcare visits approximately twice a year until age 2 years, and then annually until age 10 years. Trained research assistants collected baseline demographic information, exposure, and outcome data at each visit. Children with health conditions affecting growth (e.g. failure to thrive, cystic fibrosis), chronic conditions (except asthma), those born very premature $(<32$ weeks gestation) and children with severe developmental delay were excluded from the TARGet Kids! cohort. In addition, children who were never introduced to infant cereal as the first solid food were excluded from this study. Written consent was obtained from parents, and ethical approval granted from the Research Ethics Board (REB) at St. Michael's Hospital and The Hospital for Sick Children.

Exposure Variable 
The primary exposure was parent reported timing of introduction of infant cereal as the first solid food measured continuously (Appendix D). Caregivers completed a nutrition questionnaire adapted from the Canadian Community Health Survey ${ }^{138}$ which included the question "At what age did you introduce infant cereal to your child? (months)." The first response following the introduction to infant cereal was used.

\section{Outcome Variables}

The primary outcome variable was zBMI. Secondary outcomes included weight status categories (i.e. underweight, normal weight, overweight, obese), zHeight and nutrition risk measured using the NutriSTEP questionnaire (Appendix E) as well as NutriSTEP sub-scores for dietary intake and eating behaviour. ${ }^{139,140}$

Trained research assistants obtained anthropometric measurements using standardized anthropometric protocols at each primary care visit between 0 and 10 years. A precision digital scale was used for weight measurements (seca, Hamburg, Germany), a calibrated length board was used for length measurements on children under 2 years of age, and a stadiometer was used to measure height on children over 2 years of age (Health O Meter, Boca Raton (FL), United States). Weight $(\mathrm{kg})$ was divided by height squared $\left(\mathrm{m}^{2}\right)$ to determine BMI. ${ }^{141} \mathrm{WHO}$ reference growth curves, which are believed to represent optimal growth, were used to calculate the age and sex adjusted zBMI and zHeight scores. ${ }^{51,57,58,142}$ In addition, WHO zBMI cut-offs were used to determine weight status categories which were defined as underweight (zBMI <-2), normal weight $(-2 \leq \mathrm{zBMI} \leq 1)$, overweight $(1<\mathrm{zBMI} \leq 2)$, and obese $(\mathrm{zBMI}>2) .{ }^{58,143}$ 
NutriSTEP is a validated screening questionnaire used to measure nutrition risk in children 18 months to 5 years of age. ${ }^{139,140}$ NutriSTEP includes 17 equally weighted items that cover attributes of food and nutrient intake, physical growth and development, physical activity and sedentary behaviour, food security, and the feeding environment. Each question had 2-5 response options that range in score from 0 (no nutrition risk) to 4 (nutrition risk) with a total score ranging from 0 to 68 . NutriSTEP sub-scores were empirically created to measure dietary intake and eating behaviour constructs. The NutriSTEP dietary intake sub score included 6 questions: my child usually eats grain products, my child usually consumes milk products, my child usually eats fruit, my child usually eats vegetables, my child usually eats meat, fish, poultry, or alternatives, and my child usually eats "fast food" with a score between 0 and 24 . The NutriSTEP eating behaviour sub score included 5 questions: whether the child was allowed to decide how much they ate, whether they ate while watching television, the number of snacks/meals they ate per day, the presence of gagging or trouble swallowing while eating, and whether the child is not hungry at meal times because they drink all day with a score between 0 and 20. A lower score to each NutriSTEP measure indicated lower nutrition risk (i.e. a better outcome). Children without a primary healthcare visit between 18 months and 5 years were excluded from the NutriSTEP analyses.

\section{Other variables}

Covariates which may confound the relationship between timing of introduction to infant cereal and childhood growth and nutrition risk were identified a priori based on a review of the literature. These included: child sex, birth weight, gestational age, bottle feeding, sugar 
sweetened beverage (SSB) intake, cow's milk volume, parental ethnicity, reported family income, and maternal BMI. In addition, maternal height was included as a covariate in the model with zHeight as the outcome.

Child age and feeding type in the first year of life were hypothesized as potential effect modifiers. Feeding type was measured by parent response to the question "Which scenario best describes your child in the first year of life? My child received infant formula $80-100 \%$ of the time (was exclusively formula fed); My child received breast milk $80-100 \%$ of the time (was exclusively breastfed); or, My child received both breast milk and formula equally."

Statistical Analysis

Descriptive statistics were performed to describe the primary exposure, outcomes, and covariates from each child's initial primary healthcare visit. Categorical variables were expressed as counts and percentages, and continuous variables as mean and standard deviation (SD).

For the primary analysis, linear mixed effects (LME) modelling was used to evaluate the adjusted relationship between time introduced to infant cereal and zBMI. ${ }^{144}$ For the secondary analysis, LME was used to determine the adjusted relationship between time introduced to infant cereal and zHeight, NutriSTEP score, and NutriSTEP dietary intake and eating behaviour sub scores. All LME models included the exposure and covariates specified above, and subject specific random intercepts. To determine the relationship between timing of introduction to infant cereal and weight status categories, multinomial generalized estimating equation (GEE) 
models were used with a time-exchangeable correlation structure and robust variance measures. ${ }^{145}$ All models accounted for possible non-linear effects of age. ${ }^{146,147}$

It was determined a priori to model time introduced to infant cereal non-linearly in all analyses because existing literature suggests a non-linear relationship may exist. ${ }^{12,105}$ Due to the nonlinearity, pairwise comparisons using estimated marginal means were used to compare differences in estimated mean outcome values for introduction to infant cereal at 4 months and 5 months to 6 months (the reference), as recommended by the WHO. ${ }^{148}$ Non-linearity was accounted for in all models using restricted cubic splines (RCS) with 5 knots placed at prespecified quantiles. ${ }^{146,147}$ Interaction terms were included in the final model if the likelihood ratio test result was $P<0.30 .{ }^{146}$ For models with child age as an interaction, results were reported at 1 , 5 and 10 years of age.

All exposures, outcomes and covariates had $\leq 17 \%$ missing data. Multiple imputation was used with 20 imputed data sets to account for missing data with all covariates, outcomes, and exposure in the models. ${ }^{149}$ Missing data were believed to be missing at random conditional on the variables in the imputation models. The variance inflation factor (VIF) was $<2$ for all covariates in each model. Results were considered statistically significant with $P<0.05$. All statistical analyses were conducted using $\mathrm{R}$ version $3.6 .1 .^{150}$

\subsection{Results}

A total of 9427 children participated in the TARGet Kids! cohort study between June 2008 and August 2019. After removing children who were never introduced to infant cereal $(n=484$, 
5.1\%), 8943 children were included in the growth analyses (Figure 2). The primary reason for not introducing infant cereal was not yet being introduced to solid foods $(\mathrm{n}=469,5.0 \%) .7007$ children 18 months to 5 years of age had NutriSTEP measured and were included in the nutritional risk analysis.

The mean age at the initial visit was 1.6 years, and $52.5 \%$ were male. Children were followed on average for 4.4 years. The mean age of introduction to infant cereal was 5.7 months and 1558 (18.8\%) were introduced at 4 months, $1796(21.6 \%)$ at 5 months and $3713(44.7 \%)$ at 6 months (see Table 5). Fewer children who were introduced to infant cereal at 4 months were breastfeeding (46.8\%) compared to those introduced to infant cereal at 5 months $(61.7 \%)$ or 6 months $(65.8 \%)$. Otherwise, baseline characteristics were similar for children introduced to infant cereal between 4 and 6 months.

In the primary analysis, introduction to infant cereal at 4 months vs. 6 months of age was associated with 0.06 (95\% CI: $0.01,0.12 ; P=0.03), 0.03$ (95\% CI: $-0.03,0.08 ; P=0.39)$ and 0.17 ( $95 \%$ CI: $0.06,0.28 ; P=0.002$ ) higher zBMI at 1,5 and 10 years of age, respectively. For example, at 10 years of age, it was estimated that children who were introduced to infant cereal at 4 months vs. 6 months of age had a 0.17 higher zBMI, which corresponds to a $0.7 \mathrm{~kg}(95 \% \mathrm{CI}$ : $0.2,1.2 ; P=0.002)$ higher weight for a 10 year old of average height. Children who were introduced to infant cereal at 4 months vs. 6 months had higher odds of obesity at 10 years of age (OR 1.82; 95\% CI: 1.18,2.80; $P=0.006$ ) (Table 6 and Figure 3A). The probability of obesity at 10 years of age was $5.1 \%$ for children who were introduced to infant cereal at 6 months of age and $12.3 \%$ for those introduced to infant cereal at 4 months of age. 
In the secondary analysis, children who were introduced to infant cereal at 4 months vs. 6 months of age had 0.09 (95\% CI: $0.04,0.15 ; P=0.002)$ higher zHeight at 1 year of age. However, evidence of an association with zHeight was not found at 5 years (estimate: $-0.02 ; 95 \% \mathrm{CI}$ : -0.08 , $0.04 ; P=0.53$ ) or 10 years (estimate: $0.03 ; 95 \% \mathrm{CI}:-0.08,0.14 ; P=0.63$ ) of age (Table 6 and Figure 3B).

In the nutrition risk analyses, children introduced to infant cereal at 4 months vs. 6 months had 0.24 unit higher total NutriSTEP score ( $95 \%$ CI: $-0.03,0.51 ; P=0.08), 0.09$ unit higher NutriSTEP dietary intake sub score ( $95 \% \mathrm{CI}$ : $-0.06,0.25 ; P=0.22)$, and 0.18 unit higher NutriSTEP eating behaviour sub score $(95 \% \mathrm{CI}$ : $0.07,0.29 ; P=0.001)$ between 18 months and 5 years of age (Table 7 and Figure 3C-E).

There was little difference in outcomes between children introduced to infant cereal at 5 and 6 months (Figure 4). There was no evidence that breast/formula feeding in the first year of life was an effect modifier for any of the outcomes $(P>0.30)$.

\subsection{Discussion}

In this longitudinal cohort study, the relationship between the timing of introduction to infant cereal between 4 and 6 months of age and growth and nutrition risk were examined up to 10 years of age. Introduction of infant cereal at 4 months vs. 6 months of age was associated with higher zBMI throughout childhood with a peak weight difference of approximately $0.7 \mathrm{~kg}$ and 2fold higher odds of obesity at 10 years of age. A weight difference of $0.7 \mathrm{~kg}$ is one-quarter of the 
distance between major percentile lines on the WHO growth chart at 10 years of age. ${ }^{58,151}$ Introduction of infant cereal at 4 months vs. 6 months was associated with higher height $(0.23 \mathrm{~cm}$ on average) at 1 year of age which was not detectable by 5 and 10 years of age and worse NutriSTEP eating behaviour sub-score between 18 months and 5 years of age. Taken together, these findings support current AAP and WHO recommendations for introducing solid food around 6 months of age.

Several previous studies have examined the relationship between timing of introduction to solid food and child growth, but few have differentiated between the 4 to 6 month period. A recent systematic review on the timing of introduction to solid foods found there was little evidence that introduction at 4 and 5 months vs. 6 months was associated with weight gain or length in childhood. Although, the authors noted a number of limitations in the existing literature including lack of granularity on the timing of introduction to solid food between 4 and 6 months of age, poor understanding of the effect of early milk feeding (i.e. breast or formula) and lack of evaluation of multiple outcomes (i.e. weight, height and feeding behaviour). ${ }^{14}$ Huh et al. found that formula fed children who were introduced to solid foods $<4$ months or $\geq 6$ months had greater odds of obesity $\left(\geq 95^{\text {th }}\right.$ percentile) at 3 years $(n=847)$ and similar patterns were found in early adolescence in a follow-up study by Gingras et al. $(n=1013) .{ }^{125,152}$ Our findings extend this work by suggesting that within the 4 to 6 month window of solid food introduction, differences in growth and nutrition persist into later childhood.

It has been suggested that there may be a sensitive period in feeding skill development when solid foods are most easily accepted. ${ }^{126,127}$ Coulthard et al. and Northstone et al. found that 
children who were introduced to lumpy solid foods $<6$ months compared to 6-9 months or $>9$ months had less feeding difficulties at 6 months, 15 months, and 7 years of age $(n=7821) .{ }^{116,117}$ Hollis et al. showed that children who were introduced to solid food at $\geq 6$ months, compared to 4-5 months, had lower risk of feeding difficulties at 3 years of age $(n=2389) .{ }^{118}$ Similarly, Abraham et al. showed children who started solid foods a 4-5 months or 6-10 months compared to $0-3$ months had a better eating pattern at 2 years of age $(n=5217) .{ }^{13}$ To our knowledge, no previous study has examined the association between introduction of solid foods between 4 and 6 months and nutrition risk. The most favourable NutriSTEP eating behaviour sub-score was observed when solid foods were introduced at 6 months of age. It is possible that the observed differences in adiposity following the introduction of solid foods at 4 vs. 6 months of age may be driven by differences in eating behaviors which may be an area of future research.

Strengths of this study include the longitudinal design with a large, ethnically diverse cohort of healthy urban children. Standardized physical measurements and validated questionnaires permitted evaluation of multiple clinically relevant nutritional outcomes with adjustment for important potentially confounding variables including breast or formula feeding. Follow-up through 10 years of age allowed evaluation of small differences in the timing of introduction to solid foods over a long period of time.

There are several limitations of the current study. Due to the observational nature of the study, there is the potential for unmeasured confounding, so causality cannot be established. Timing of introduction to infant cereal was used as proxy for solid food introduction and measured retrospectively by parent report which may be subject to bias. In the TARGet Kids! cohort study, 
$95 \%$ of breastfed children were introduced to infant cereal as the first solid food. To minimize the duration of recall, timing of introduction to infant cereal was measured at the first visit following introduction to infant cereal. While all models included adjustment for anthropometric measurements prior to the introduction of solid food to account for baseline growth differences, reverse causality is a possibility for some of the early growth measures. Lastly, while the TARGet Kids! cohort includes an ethnically diverse sample of healthy urban children, it may not be representative of children in other urban settings.

We suggest that future observational studies differentiate the timing of introduction to solid food between 4 and 6 months of age, assess the type and amount of foods consumed, and parental reasons for initiating solid foods to help understand the complexity of solid food introduction. While clinical trials could provide an unbiased assessment of the relationship between the timing of solid food introduction and growth and nutrition in later life, ethical and practical limitations make such studies challenging.

\subsection{Conclusion}

In this large longitudinal cohort study of healthy children who were followed through 10 years of age, introduction of infant cereal at 6 months of age was associated with lower BMI and lower odds of obesity through 10 years of age, better eating behaviour between 18 months and 5 years of age and minimal differences in linear growth. These findings support current AAP and WHO guidelines for introducing solid food around 6 months of age. 
Tables and Figures

Table 5: Participant initial visit characteristics ${ }^{\text {a }}$

\begin{tabular}{|c|c|c|c|c|}
\hline \multirow[b]{2}{*}{ Characteristics } & \multicolumn{3}{|c|}{ Time introduced to infant cereal (mo) } & \multirow{2}{*}{$\begin{array}{c}\text { Total cohor } \\
(\mathrm{n}=8943)^{\mathrm{b}}\end{array}$} \\
\hline & $\begin{array}{c}4 \\
(n=1558)\end{array}$ & $\begin{array}{c}5 \\
(n=1796)\end{array}$ & $\begin{array}{c}6 \\
(n=3713)\end{array}$ & \\
\hline \multicolumn{5}{|l|}{ Child characteristics } \\
\hline $\begin{array}{l}\text { Timing of introduction to infant } \\
\text { cereal (mo) }\end{array}$ & $4.05(0.16)$ & $5.09(0.19)$ & $6.01(0.05)$ & $5.7(2.1)$ \\
\hline Age (mo) & $21.7(19.3)$ & $18.8(19.4)$ & $25.8(18.8)$ & $24.8(19.4)$ \\
\hline \multicolumn{5}{|l|}{ Sex } \\
\hline Male & $849(54.6)$ & $944(52.7)$ & $1936(52.2)$ & $4685(52.5)$ \\
\hline Female & $707(45.4)$ & $848(47.3)$ & $1770(47.8)$ & 4239 (47.5) \\
\hline Birth weight $(\mathrm{kg})$ & $3.3(0.6)$ & $3.3(0.6)$ & $3.3(0.6)$ & $3.3(0.6)$ \\
\hline $\begin{array}{c}\text { Gestational age } \\
32-36 \mathrm{wk} \\
\geq 37 \mathrm{wk}\end{array}$ & $\begin{aligned} 122(9.1) \\
1212(90.9)\end{aligned}$ & $\begin{array}{r}132(8.4) \\
1432(91.6)\end{array}$ & $\begin{array}{c}363(11.8) \\
2711(88.2)\end{array}$ & $\begin{array}{c}802(10.8) \\
6600(89.2)\end{array}$ \\
\hline \multicolumn{5}{|l|}{$\begin{array}{l}\text { Feeding scenario in } 1^{\text {st }} \text { year of } \\
\text { life }^{\mathrm{c}}\end{array}$} \\
\hline Predominantly breast fed & $711(46.8)$ & $1085(61.7)$ & $2380(65.8)$ & $5191(59.9)$ \\
\hline Predominantly formula fed & $353(23.2)$ & $250(14.2)$ & $497(13.7)$ & $1495(17.2)$ \\
\hline Mixed & $455(30.0)$ & $424(24.1)$ & $740(20.5)$ & 1995 (22.9) \\
\hline zBMI & $-0.01(1.25)$ & $-0.13(1.16)$ & $-0.03(1.12)$ & $-0.02(1.17)$ \\
\hline zHeight & $0.44(1.33)$ & $0.42(1.24)$ & $0.26(1.30)$ & $0.32(1.29)$ \\
\hline $\begin{array}{l}\text { Daily cow milk intake } \\
\text { ( } 250 \mathrm{ml} \text { cups/day) }\end{array}$ & $1.2(1.3)$ & $1.1(1.3)$ & $1.4(1.3)$ & $1.3(1.3)$ \\
\hline $\begin{array}{l}\text { Sugar sweetened beverage } \\
\text { intake }(250 \mathrm{ml} \text { cups/day) }\end{array}$ & $0.6(1.0)$ & $0.4(0.8)$ & $0.6(1.0)$ & $0.6(1.1)$ \\
\hline \multicolumn{5}{|l|}{ Bottle use } \\
\hline Yes & $831(54.0)$ & $858(48.4)$ & $1473(40.0)$ & 3909 (44.3) \\
\hline No & $709(46.0)$ & $914(51.6)$ & $2207(60.0)$ & $4921(55.7)$ \\
\hline NutriSTEP score $^{\mathrm{d}}$ & $13.7(6.5)$ & $13.0(6.2)$ & $13.2(6.3)$ & $13.6(6.5)$ \\
\hline $\begin{array}{l}\text { NutriSTEP dietary intake sub } \\
\text { score }^{\mathrm{d}}\end{array}$ & $6.4(3.1)$ & $6.2(3.0)$ & $6.3(3.1)$ & $6.5(3.2)$ \\
\hline $\begin{array}{l}\text { NutriSTEP eating behaviour sub } \\
\text { score }^{\mathrm{d}}\end{array}$ & $4.6(2.9)$ & $4.4(2.8)$ & $4.1(2.7)$ & $4.3(2.8)$ \\
\hline \multicolumn{5}{|l|}{ Familial Characteristics } \\
\hline Maternal BMI $\left(\mathrm{kg} / \mathrm{m}^{2}\right)$ & $26.1(5.5)$ & $24.6(4.7)$ & $24.7(4.9)$ & $25.1(5.0)$ \\
\hline Maternal height $(\mathrm{cm})$ & $163(6.8)$ & $164(7.0)$ & $164(6.9)$ & $164(6.9)$ \\
\hline
\end{tabular}


Table 6: Pairwise comparisons of introduction to infant cereal at 4 vs. 6 months of age and growth between 1 and 10 years of age

\begin{tabular}{|c|c|c|c|c|c|}
\hline \multirow{2}{*}{$\begin{array}{c}\text { Age of } \\
\text { Outcome } \\
\text { measurement } \\
\text { (y) }\end{array}$} & \multicolumn{5}{|c|}{ Growth analysis } \\
\hline & $\begin{array}{c}\text { zBMI }{ }^{\mathrm{a}, \mathrm{b}} \\
(\text { Estimate }(95 \% \mathrm{CI} ; P))\end{array}$ & $\begin{array}{c}\text { zHeight }^{\mathrm{a}, \mathrm{c}} \\
(\text { Estimate }(95 \% \mathrm{CI} ; P))\end{array}$ & $\begin{array}{l}\text { Underweight }{ }^{\mathrm{a}, \mathrm{b}, \mathrm{d}} \\
(\text { OR }(95 \% \text { CI; } P))\end{array}$ & $\begin{array}{l}\text { Overweight }^{\mathrm{a}, \mathrm{b}, \mathrm{d}} \\
(\text { OR }(95 \% \mathrm{CI} ; P)\end{array}$ & $\begin{array}{c}\text { Obese }^{\mathrm{a}, \mathrm{b}, \mathrm{d}} \\
(\text { OR }(95 \% \mathrm{CI} ; P))\end{array}$ \\
\hline 1 & $0.06(0.01,0.12 ; 0.03)$ & $0.09(0.04,0.15 ; 0.002)$ & $1.08(0.85,1.38 ; 0.54)$ & $1.03(0.87,1.22 ; 0.70)$ & $1.25(0.93,1.69 ; 0.14)$ \\
\hline 5 & $0.03(-0.03,0.08 ; 0.39)$ & $-0.02(-0.08,0.04 ; 0.53)$ & $0.72(0.43,1.22 ; 0.22)$ & $1.05(0.89,1.24 ; 0.55)$ & $1.28(0.96,1.71 ; 0.10)$ \\
\hline 10 & $0.17(0.06,0.28 ; 0.002)$ & $0.03(-0.08,0.14 ; 0.63)$ & $0.32(0.08,1.23 ; 0.10)$ & $1.12(0.80,1.62 ; 0.54)$ & $1.82(1.18,2.80 ; 0.006)$ \\
\hline \multicolumn{6}{|c|}{$\begin{array}{l}\text { a All models adjusted for predominant feeding type in first year of life (breast milk, formula, or mixed), birth weight, child sex, gestational age, } \\
\text { parental ethnicity, family income, SSB intake, cow's milk volume, bottle feeding and non-linear time introduced to infant cereal (RCS, } 5 \text { knots). } \\
\text { Introduction to infant cereal at } 6 \text { mo is the reference group. } \\
\text { b Also adjusted for maternal BMI and child age (RCS, } 5 \text { knots) as effect modifier } \\
{ }^{c} \text { Also adjusted for maternal height and child age (RCS, } 5 \text { knots) as effect modifier } \\
\text { d Normal weight reference category (-2 } \leq \text { zBMI } \leq 1)\end{array}$} \\
\hline
\end{tabular}


Table 7: Pairwise comparisons of introduction to infant cereal at 4 vs. 6 months of age and nutrition risk between 1 and 5 years of age

\begin{tabular}{|c|c|c|c|}
\hline \multirow{2}{*}{$\begin{array}{l}\text { Age of } \\
\text { outcome } \\
\text { measurement } \\
\text { (y) }\end{array}$} & \multicolumn{3}{|c|}{ Nutrition risk analysis } \\
\hline & $\begin{array}{l}\text { NutriSTEP total score } \\
\text { (Estimate }(95 \% \text { CI; } P))\end{array}$ & $\begin{array}{l}\text { Dietary intake sub-score } \\
\text { (Estimate }(95 \% \text { CI; } P))\end{array}$ & $\begin{array}{l}\text { Eating behaviour sub- } \\
\text { score }^{\mathrm{a}} \\
(\text { Estimate }(95 \% \mathrm{CI} ; \boldsymbol{P}))\end{array}$ \\
\hline $1-5$ & $0.24(-0.03,0.51 ; 0.08)$ & $0.09(-0.06,0.25 ; 0.22)$ & $0.18(0.07,0.29 ; 0.001)$ \\
\hline \multicolumn{4}{|c|}{$\begin{array}{l}\text { all models adjusted for predominant feeding type in first year of life (breast milk, formula, or } \\
\text { mixed), birth weight, child sex, gestational age, parental ethnicity, family income, bottle feeding, } \\
\text { maternal BMI, child age (RCS, } 5 \text { knots) and non-linear time introduced to infant cereal (RCS, } 5 \\
\text { knots). Introduction to infant cereal at } 6 \text { mo is the reference group. }\end{array}$} \\
\hline
\end{tabular}


Figure 2: Participant flow chart

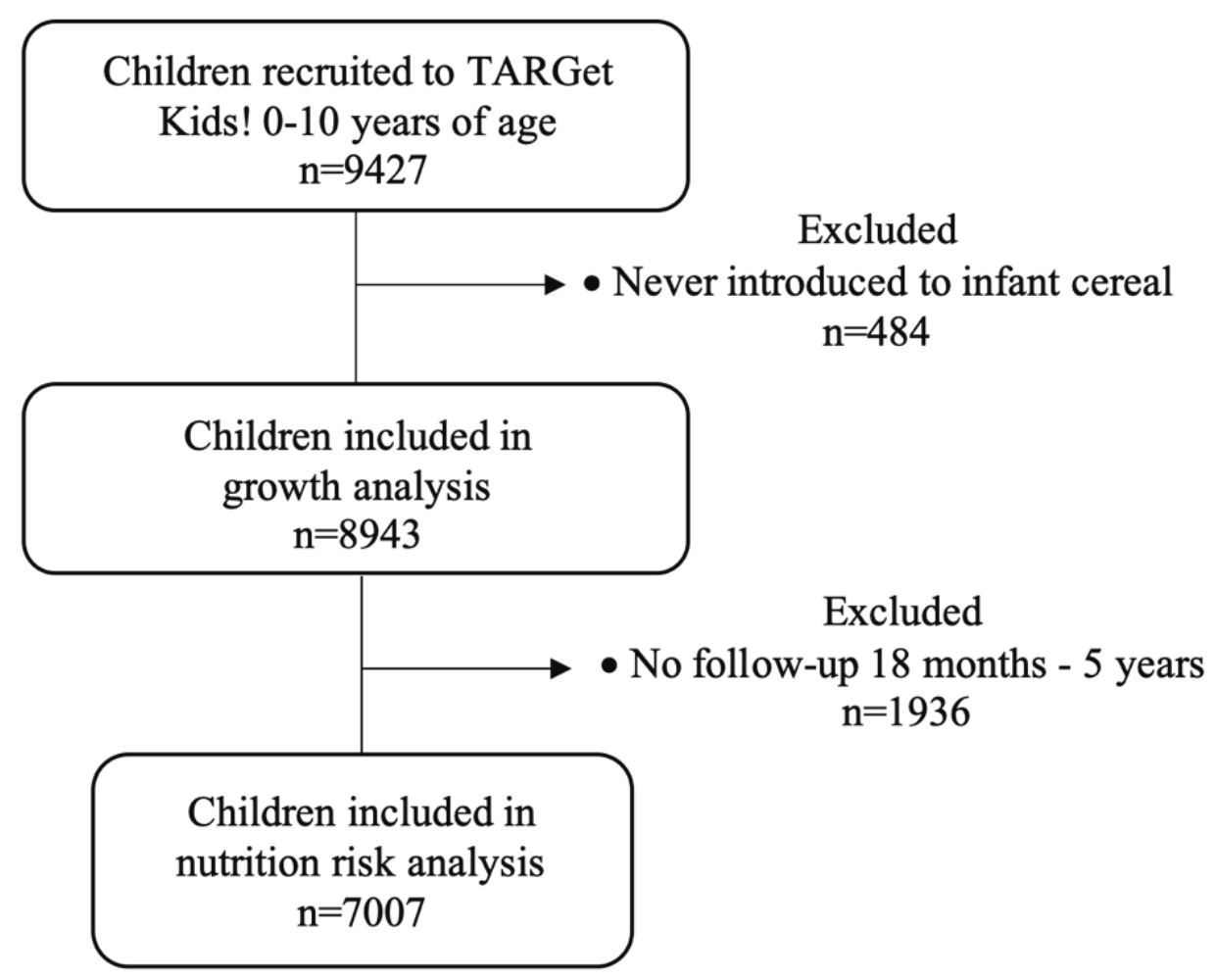

Nutrition Screening Tool for Toddlers and Preschoolers (NutriSTEP) administered between 18 mo and 5 years of age 
Figure 3: Association between time introduced to infant cereal (4-6 mo) and growth and nutrition risk

A Time introduced to infant cereal and BMI z-score

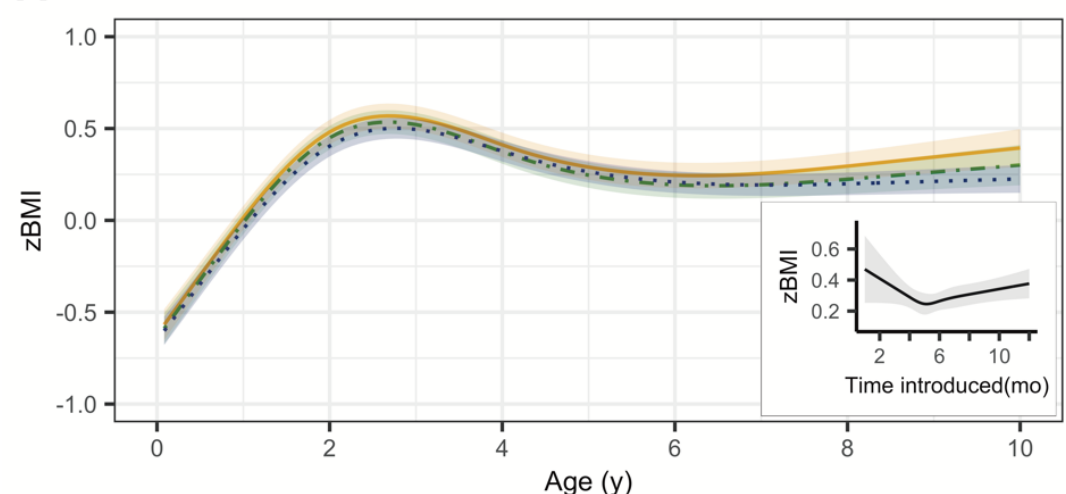

C Time introduced to infant cereal and NutriSTEP score

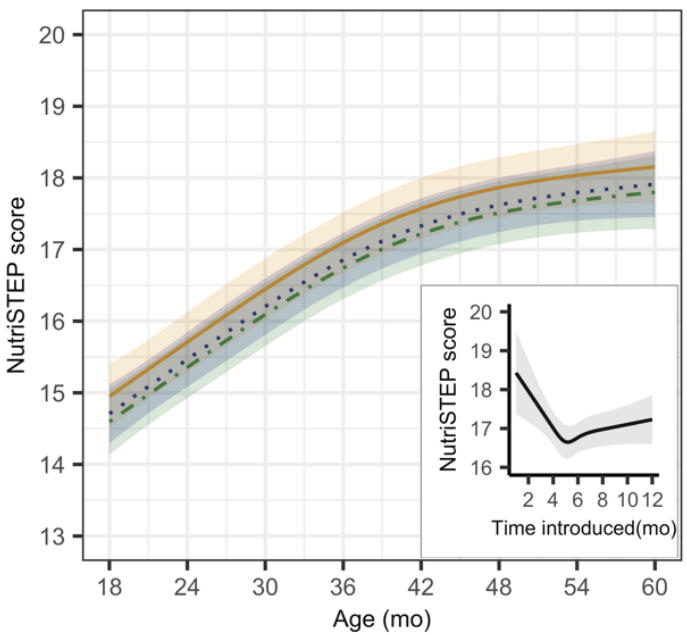

B Time introduced to infant cereal and height z-score

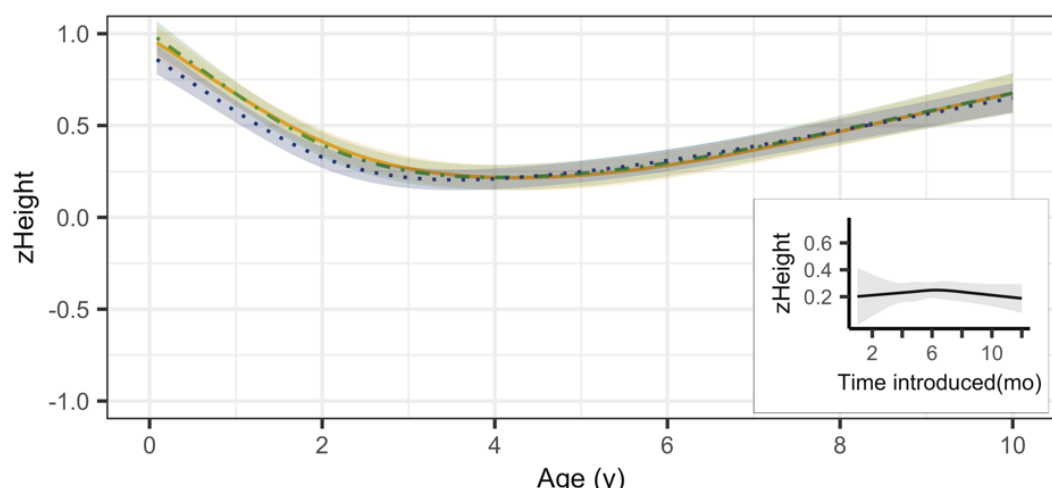

E Time introduced to infant cereal and Eating Behaviour (EB) score

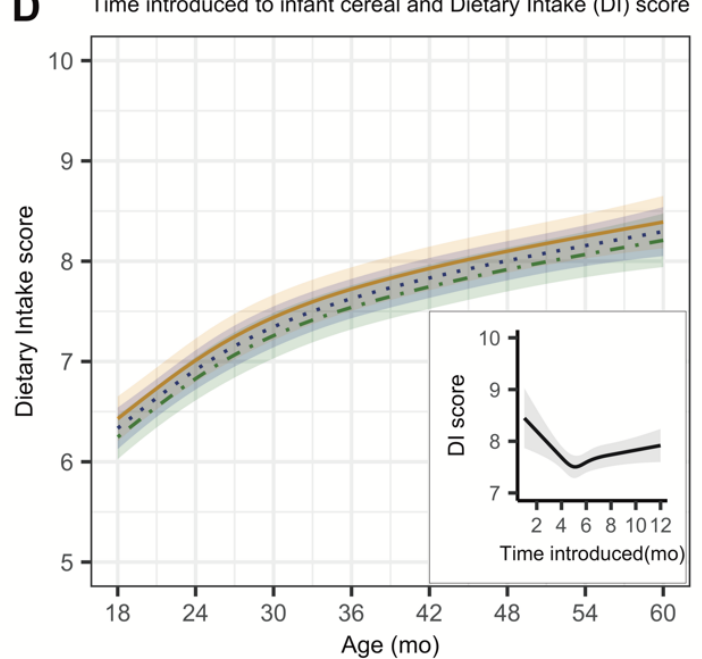

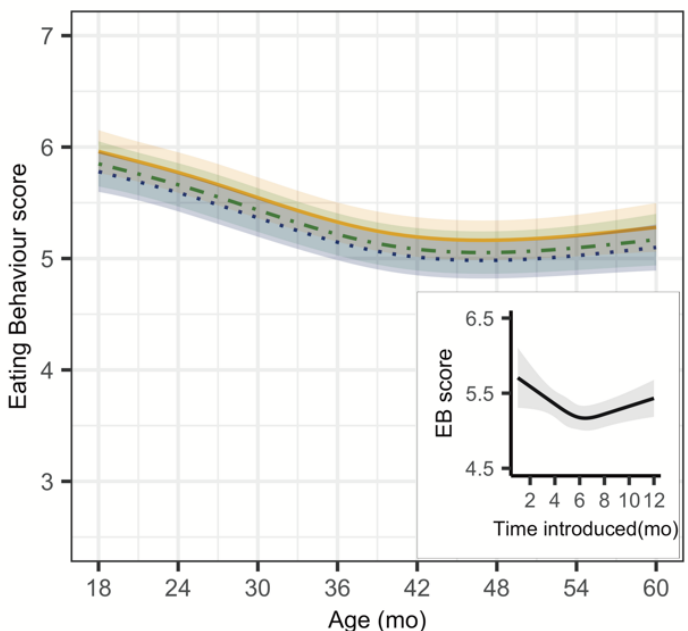

Time introduced to infant cereal (mo) $\quad 4 \quad-\cdot 5 \cdots 6$

Legend: A-B, non-linear models with child age as effect modifier (in-laid plot shown at 5 years); C-E, non-linear model; A-E, also adjusted for variables described in text. Shaded area represents $95 \% \mathrm{CI}$ 
Figure 4: Timing of introduction to infant cereal (4-6 mo) pairwise comparisons by child age (y) for growth and nutrition risk
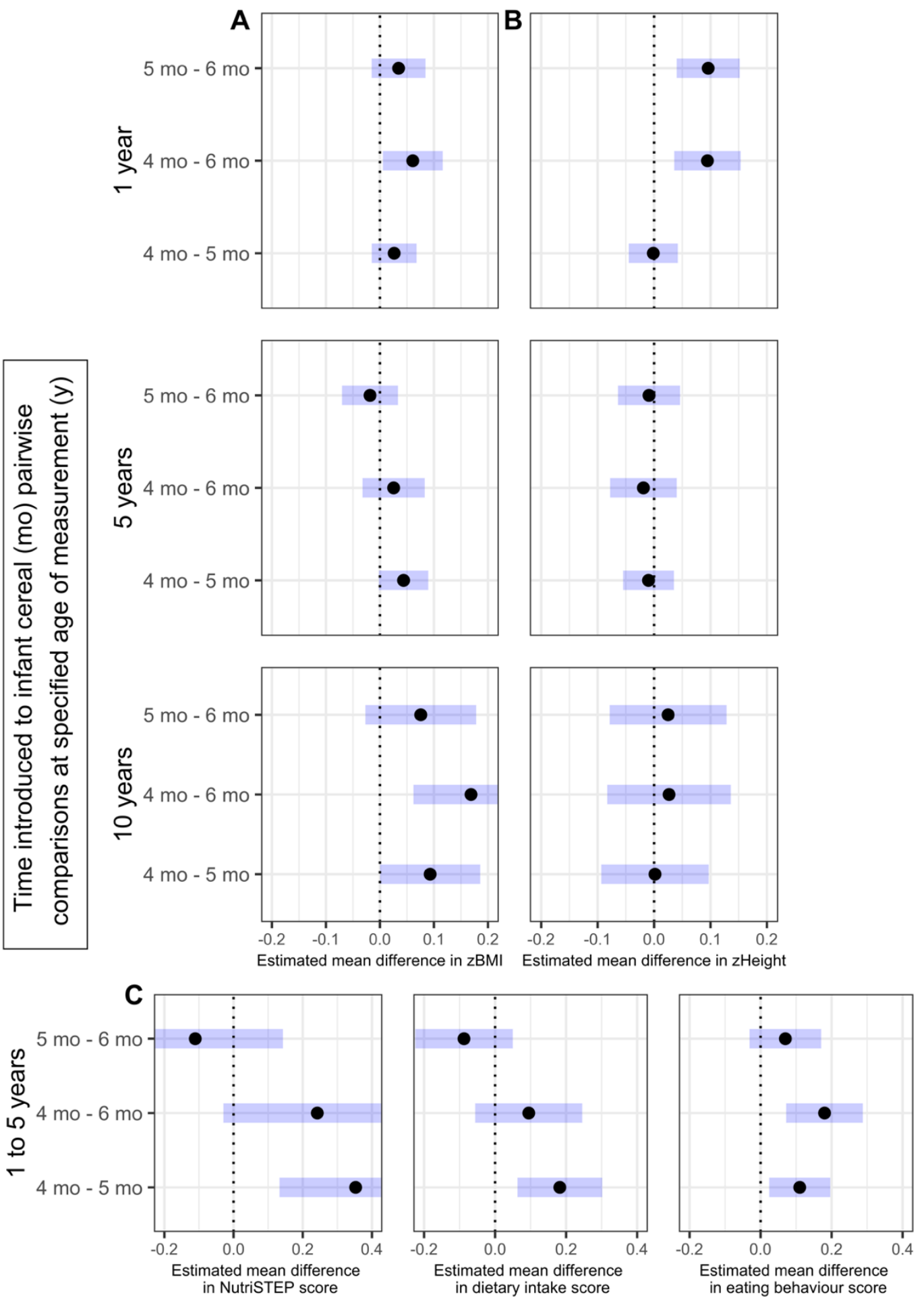

Legend: A-B, non-linear models with child age as effect modifier; $\mathbf{C}$, non-linear models; A-C, also adjusted for variables described in text. Shaded area represents $95 \% \mathrm{CI}$ for pairwise comparison tests; confidence intervals which do not cross 0 are statistically different from one another $(P<0.05)$. Introduction to infant cereal at $6 \mathrm{mo}$ is the reference group for the first two comparisons and 5 mo is the reference group for the third comparison (i.e. 4 mo -5 mo). 


\section{CHAPTER 4: OVERALL DISCUSSION}

In this thesis I have examined the relationship between the timing of introduction to infant cereal as the first solid food in the 4 to 6 months range and growth and nutrition risk. I also explored the role of breast/formula feeding and the age of the child in this relationship. Given that all caregivers must introduce solid food to their child's diet, the results of this study are relevant to many. I determined my hypothesis, research questions and methodology a priori (Appendix F) and followed through with this plan. I identified that the introduction to infant cereal at 6 months, compared to 4 months, was associated with lower BMI and lower odds of obesity, better eating behaviour and minimal differences in height. Furthermore, there was minimal difference in growth or nutritional risk for those introduced to infant cereal at 6 months, compared to 5 months, and breast/formula feeding did not modify any of the relationships.

Previous research findings have shown that introduction to solid foods $\leq 4$ months results in a greater BMI. ${ }^{12,107,125}$ It has also been suggested that children introduced to solid food $\geq 7$ months have a greater BMI. ${ }^{12}$ Although less is known about differences in the 4 to 6 months range, I hypothesized that children introduced to solid food at 4 months, compared to 6 months, would have a more unhealthy BMI. This hypothesis is supported by the proposed mechanism that introducing solid food earlier increases protein intake which subsequently increases BMI. Furthermore, fewer children are introduced to solid food $\geq 7$ months, and thus, less is known about their health outcomes. For instance, the study by Sun et al. noted that the finding of children introduced to solid foods $\geq 7$ months having an increased BMI be interpreted with caution due to the small number of participants in this group. ${ }^{12}$ 
In the present study, most children were introduced to infant cereal at 6 months of age which aligns with current Canadian guidelines. The next two most common times to introduce infant cereal was 5 months and 4 months. I identified that children introduced to infant cereal at 4 months, compared to 6 months, had a greater zBMI at 1, 5, and 10 years of age. By 10 years of age, children introduced to infant cereal at 4 months, compared to 6 months, had nearly double the odds of obesity. Differences in zBMI were not apparent between children introduced to infant cereal at 5 months compared to 6 months.

To my knowledge, only 2 previous studies have been able to differentiate between introduction to solid food in the 4 to 6 months range while examining growth. Sun et al. conducted a crosssectional study in Melbourne, Australia as part of the HealthNuts study ( $\mathrm{n}=3153) .{ }^{12}$ Self-reported age of introduction to solid foods was collected and categorized into 5 groups: $<4 \mathrm{mo}, 4 \mathrm{mo}, 5 \mathrm{mo}$, $6 \mathrm{mo}$, and $>6 \mathrm{mo}$. Similar to the present study, Sun et al. found that children introduced to solid food at 4 months, compared to 6 months, had increased odds of obesity. However, Sun et al. followed-up with participants at only 1 year of age, included self-reported height/weight and did not adjust for maternal BMI. ${ }^{12}$ Seach et al. conducted a prospective cohort study in Melbourne, Australia as part of the Melbourne Atopy Cohort Study (MACS) ( $n=307)$. Telephone interviews were used to record when solid foods were first introduced (measured continuously in weeks). A non-linear relationship was tested for, however, modelling a linear relationship was found to be more appropriate. Later introduction to solid foods was found to reduce the odds of being overweight/obese at 10 years of age. Children included in the MACS were at high risk of developing atopy and it is not clear how generalizable the results are to other populations. 
Furthermore, Seach et al. included a modest sample size, was unable to adjust for maternal BMI and lost about $50 \%$ of the cohort to follow-up by 10 years of age.

Although causality cannot be established in the present work, well-designed observational studies are important as practical and ethical limitations make RCTs difficult to conduct. To my knowledge, only two RCTs have been conducted in resource rich settings in relation to the timing of introduction to solid food and growth. Both RCTs examined the introduction of solid foods at 4 vs. 6 months of age with Bainbridge et al. conducting their study in the United States among formula fed children, and Jonsdottir et al. conducting their study in Iceland among breastfed children. ${ }^{109,111}$ Neither study detected a difference in BMI, although, they were small trials and lacked participant diversity. ${ }^{109,111}$ Randomizing children to start solid food at 4 vs. 6 months could be challenging. An RCT which randomizes children to a health promotion intervention for delaying the introduction of solid foods to 6 months vs. usual care may be feasible and help address remaining gaps in the literature. For example, the Promotion of Breastfeeding Intervention Trial (PROBIT) randomly assigned hospitals and clinics to follow a breastfeeding support model or continue with usual care.$^{80}$ The experimental arm resulted in a higher frequency of breastfeeding. ${ }^{80} \mathrm{~A}$ similar approach could be taken for solid food introduction.

Few studies have identified a relationship between the timing of introduction to solid food and length/height. The RCT conducted by Bainbridge et al. found that children introduced to cereal at 4 months had a greater increase in length between 4 and 6 months compared to those exclusively formula fed through the first 6 months of life. ${ }^{109}$ However, no significant difference 
in length was detected at 6 months of age. ${ }^{109}$ Otherwise, numerous studies have demonstrated the lack of association between time introduced to solid food and height. ${ }^{11,114,125} \mathrm{BMI}$ is determined by dividing weight $(\mathrm{kg})$ by height squared $\left(\mathrm{m}^{2}\right)$. Thus, a decrease in height would increase BMI with weight held constant. We hypothesized that introduction to infant cereal at 4 months compared to 6 months may negatively impact height in later childhood. This was to align with our hypothesis that introduction to infant cereal at 4 months compared to 6 months would be associated with a higher zBMI so that a shorter stature may explain some of the difference. We found that introduction to infant cereal at 4 months compared to 6 months resulted in a $0.23 \mathrm{~cm}$ larger height at 1 year of age, on average, but no difference was found at 5 or 10 years of age. A $0.23 \mathrm{~cm}$ difference at 1 year of age is likely not a clinically meaningful difference. Furthermore, it was surprising to see that at 1 year of age those introduced to infant cereal at 4 months, compared to 6 months, had a larger height and BMI. This would suggest that an increase in weight was driving the difference in BMI.

Nutritional risk has been defined as the presence of risk factors leading to impaired nutritional status. ${ }^{115}$ Risk factors can include food and nutrient intake, the feeding environment and feeding difficulties. The heterogeneity in measuring nutrition risk makes it challenging to draw conclusions from the existing literature. Furthermore, the timing of introduction to solid food in the 4 to 6 months range and nutrition risk has not been previously studied. We hypothesized that introduction to infant cereal at 4 months, compare to 6 months, would result in a worse nutrition risk. We found that introduction to infant cereal at 4 months resulted in a worse NutriSTEP eating behaviour score, but no difference was detected in NutriSTEP total score nor dietary intake score. The Avon Longitudinal Study of Parents and Children (ALSPAC) developed a self- 
reported questionnaire for measuring feeding difficulties. The questionnaire includes six questions which parents rate on a four-point Likert scale: (1) whether they felt there had been difficulties feeding their child, (2) not eating sufficient amounts of food, (3) refusal to eat the right food, (4) being choosy with food, (5) over-eating and (6) being difficult to get into a feeding routine. ${ }^{117}$ This questionnaire is similar to the NutriSTEP eating behaviour sub score which includes 5 questions: (1) whether the child was allowed to decide how much they ate, (2) whether they ate while watching television, (3) the number of snacks/meals they ate per day, (4) the presence of gagging or trouble swallowing while eating and (5) whether the child is not hungry at meal times because they drink all day. The prospective cohort study conducted by Hollis et al. was most similar to the present study. ${ }^{118}$ Hollis et al. examined the relationship between timing of introduction to solid food and nutrition risk measured using the ALSPAC questionnaire. The main finding was a reduction in feeding difficulties for those introduced to solid food $\geq 6$ months compared to $4-5$ months. ${ }^{118}$ Northstone et al. and Coulthard et al. also measured feeding difficulties using the ALSPAC questionnaire. However, their primary exposure was timing of introduction to "lumpy" solids and the generalizability to timing of introduction to any solids isn't clear.

\section{Strengths}

There were a number of strengths of the current study. TARGet Kids! is a large ethnically diverse cohort of healthy urban children who were followed through 10 year of age. The longitudinal nature of the study design allowed evaluation of the temporal relationship between the timing of introduction to infant cereal in the 4 to 6 months range and health outcomes. Standardized physical measurements and validated questionnaires permitted evaluation of 
multiple clinically relevant nutritional outcomes with adjustment for potentially confounding variables. Notably, we were able to test if breast or formula feeding modified any of the relationships. All anthropometric measurements were converted to z-scores relative to the WHO growth standard/reference increasing the generalizability of the results and an understanding if the children were growing "normally". Furthermore, some study participants had data prior to the introduction to infant cereal and thus, we were able to adjust for baseline differences and minimize the possibility for reverse causality.

Pre-specified hypotheses were investigated and the statistical analysis plan was developed $a$ priori. Timing of introduction to infant cereal was measured continuously and we were able to model all relationships non-linearly. LME and GEE were used to account for the cluster of repeated measures among subjects. Multiple imputation was used to account for missing data under the missing at random assumption for all variables. A complete case analysis would have introduced bias into the results.

\section{Limitations}

There are several limitations of the current study. Due to the observational nature of the study, there is the potential for unmeasured confounding, so causality cannot be established. Timing of introduction to infant cereal was used as proxy for solid food introduction and measured retrospectively by parent report which may be subject to bias. In the TARGet Kids! cohort study, $95 \%$ of breastfed children were introduced to infant cereal as the first solid food. To minimize the duration of recall, timing of introduction to infant cereal was measured at the first visit following introduction to infant cereal. While all models included adjustment for anthropometric 
measurements prior to the introduction of infant cereal to account for baseline growth differences, reverse causality is still a possibility for some of the early growth measures. Lastly, while the TARGet Kids! cohort includes an ethnically diverse sample of healthy urban children, it may not be representative of children in other urban settings. Lastly, selection bias is a possibility. Parents who consent to participate in the TARGet Kids! cohort may be different from those who did not. Additionally, children excluded from the growth and nutrition risk analysis and those excluded from the nutrition risk analysis alone may differ from those included. However, when I compared initial visit characteristics for children included vs. excluded in the analyses the groups appeared to be similar.

\section{Future Research}

This study has highlighted a number of future areas of study which warrant investigation. First, the clinically relevant time to introduce solid food is in the 4 to 6 month range. Future studies should distinguish between this range which would help to confirm this study's findings. Second, data should be collected on parental reasons for introducing solid foods. This can provide important insights for reverse causality and also identify areas for caregiver education. Third, detailed information on when specific foods are introduced can help elucidate the mechanism and also inform policy for the timing of introduction of specific foods. For instance, it is possible that protein rich foods being offered early and often drive the differences in growth. Similarly, future studies should either adjust for nutrition risk as a confounding variable while exploring the relationship between the timing of introduction to solid foods and growth, or explore its role as a mediating variable in this relationship. Fourth, this study examined two important child health indicators in growth and nutrition risk. However, it is known that timing of introduction to solid 
food is also related to outcomes such as micronutrient stores, allergy risk and gastrointestinal and respiratory infections which were not examined. Collecting information on these variables would be important in informing future guidelines and determining the optimal time to introduce solid foods. Lastly, clinical trials should be conducted to determine causality. These studies should be highest priority but ethical and practical limitations make them challenging to conduct. 


\section{CHAPTER 5: CONCLUSION}

In this thesis, I have identified that children introduced to infant cereal at 6 months, compared to 4 months, had lower zBMI and lower odds of obesity, better eating behaviour and minimal differences in zHeight through 10 years of age. There were minimal differences in growth or nutrition risk for those introduced to infant cereal at 6 months, compared to 5 months.

Breast/formula feeding in the first year of life did not modify any of the relationships. Current Canadian and WHO recommendations for introducing solid foods at 6 months of age appear to be appropriate for optimal growth and eating behaviour. Future observational and clinical trial studies are needed to confirm these findings. 


\section{CHAPTER 6: APPENDIX}

Appendix A: WHO child growth standards (0-5 year) and reference (5-19 years) - girls BMIfor-age $\mathrm{z}$-scores

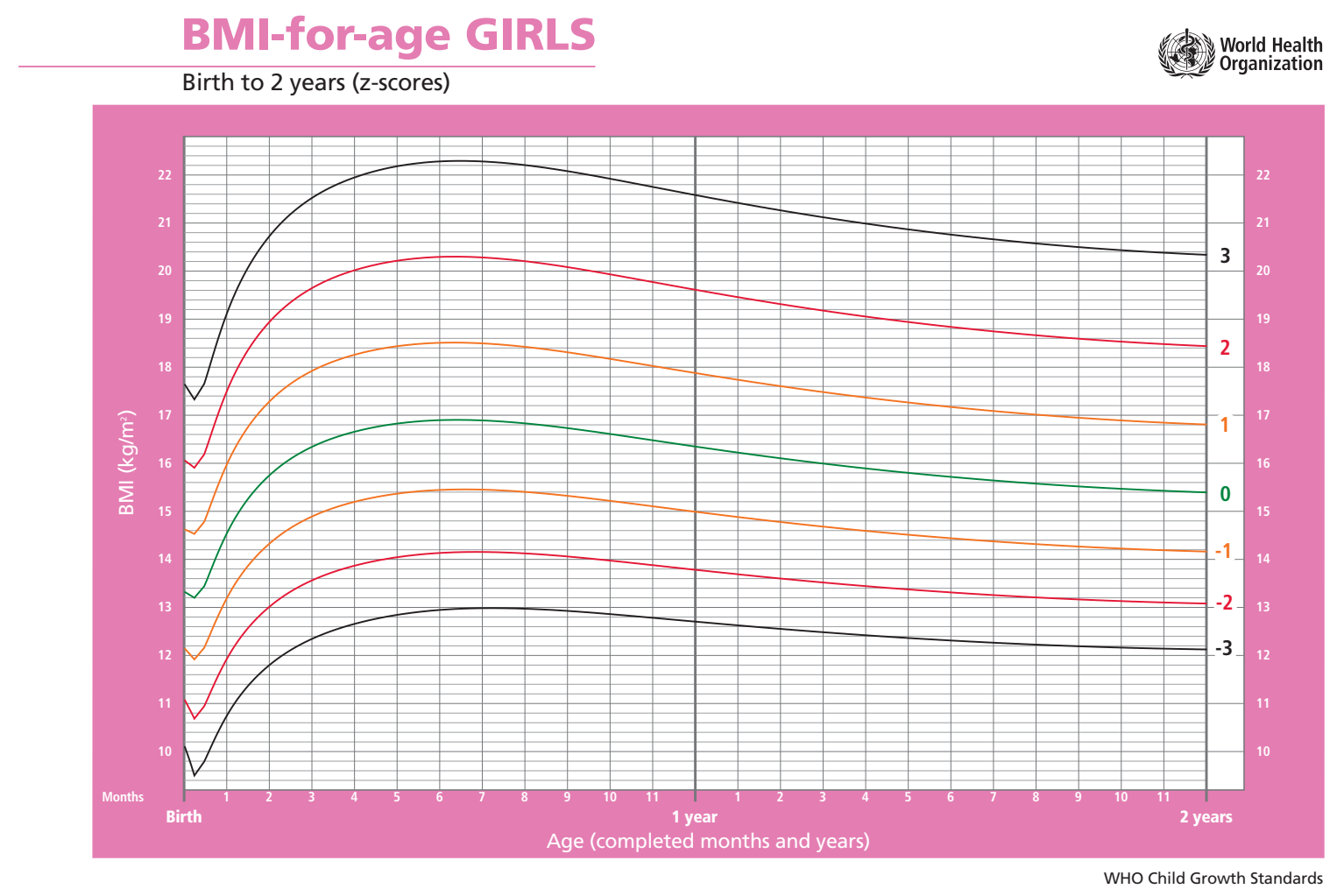


BMI-for-age GIRLS

2 to 5 years (z-scores)

World Health

Oe Organization

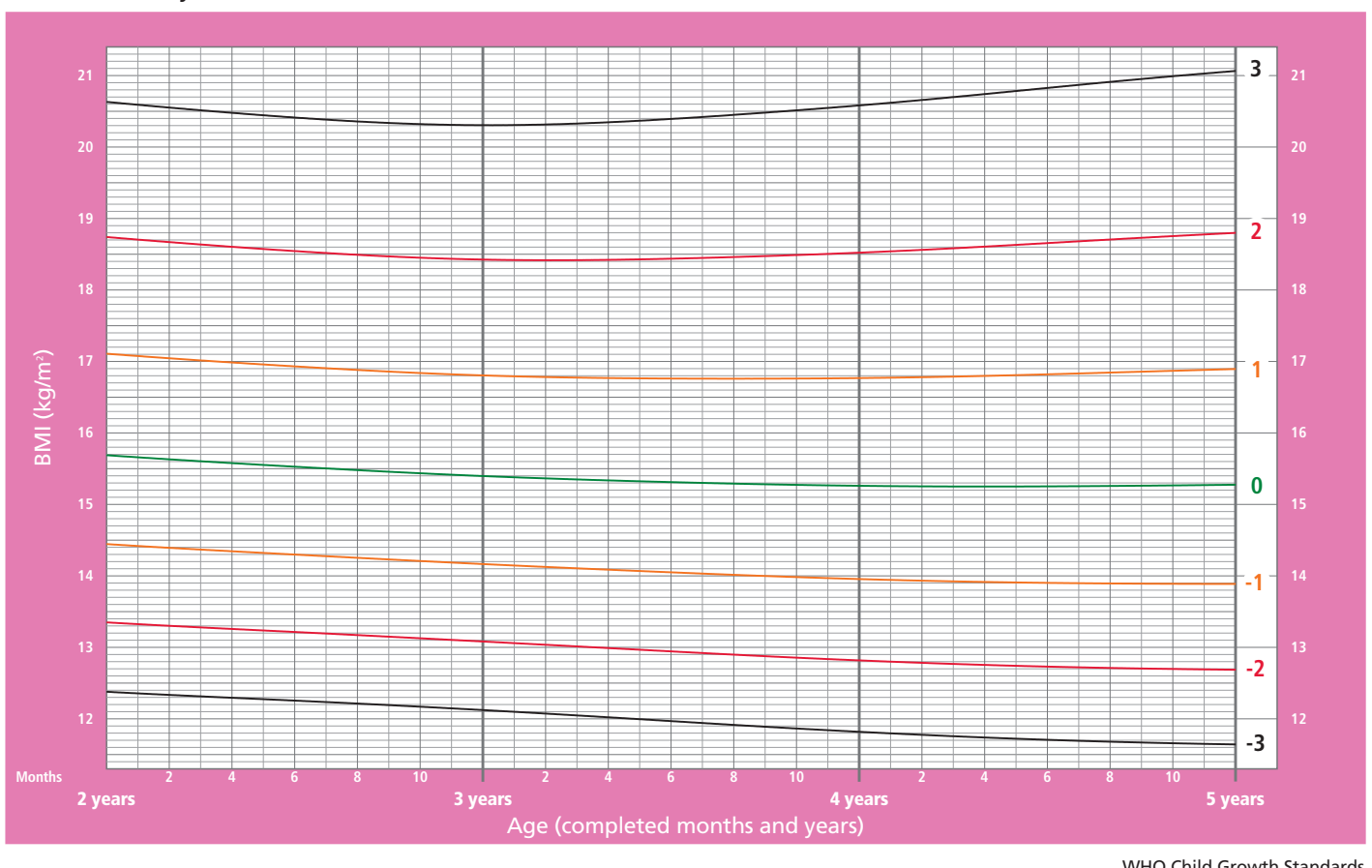

WHO Child Growth Standards 
BMI-for-age GIRLS

5 to 19 years (z-scores)

World Health
Organization

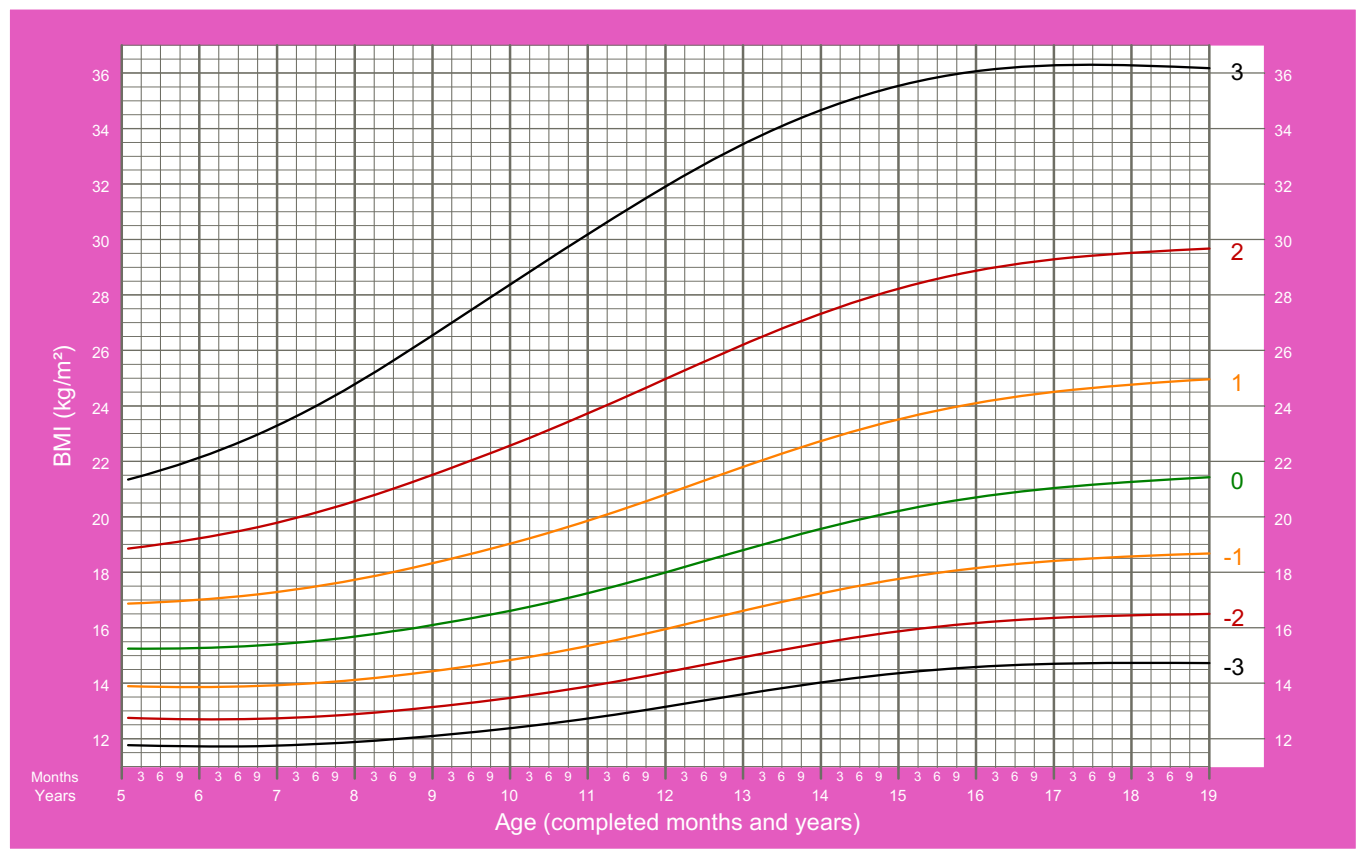

2007 WHO Reference 
Appendix B: Summary of previous studies evaluating the relationship between the timing of introduction to solid food and growth

\begin{tabular}{|c|c|c|c|c|}
\hline First author, country, year & Study design, n & $\begin{array}{l}\text { Independent variable or } \\
\text { exposure }\end{array}$ & $\begin{array}{l}\text { Outcome measures and age } \\
\text { of follow-up }\end{array}$ & Results \\
\hline \multicolumn{5}{|c|}{ Randomized Controlled Trials } \\
\hline $\begin{array}{l}\text { Bainbridge, } \\
\text { United States, } \\
1996\end{array}$ & $\begin{array}{l}\mathrm{RCT}, \\
41\end{array}$ & $\begin{array}{l}\text { Formula plus cereals age } \\
16-26 \text { weeks vs. formula } \\
\text { alone age } 16-26 \text { weeks }\end{array}$ & $\begin{array}{l}\cdot \text { Weight, length } \\
\text {-26 weeks }\end{array}$ & $\begin{array}{l}\cdot \text { No difference in weight } \\
\cdot \text { Change in length from } 16 \text { to } 26 \text { wk higher for early } \\
\text { introduction to cereal group ( } \mathrm{p}=0.05 \text { ) }\end{array}$ \\
\hline $\begin{array}{l}\text { Jonsdottir, } \\
\text { Iceland, } \\
2014\end{array}$ & $\begin{array}{l}\mathrm{RCT} \\
119\end{array}$ & $\begin{array}{l}\text { Breastmilk plus } \\
\text { complementary foods } 4-6 \\
\text { months vs. exclusive } \\
\text { breastmilk to } 6 \text { months }\end{array}$ & $\begin{array}{l}\cdot \text { BMI, weight, length } \\
\cdot 29-38 \text { months of age }\end{array}$ & $\begin{array}{l}\text { - No difference in BMI }(\mathrm{p}=0.45) \\
\text { - No difference in weight }(\mathrm{p}=0.78) \\
\text { - No difference in length }(\mathrm{p}=0.59)\end{array}$ \\
\hline \multicolumn{5}{|l|}{ Observational Studies } \\
\hline $\begin{array}{l}\text { Sun, } \\
\text { Australia, } \\
2016\end{array}$ & $\begin{array}{l}\text { Cross-sectional, } \\
3153\end{array}$ & $\begin{array}{l}\text { Introduction to solid foods } \\
<4 \mathrm{mo}, 4 \mathrm{mo}, 5 \mathrm{mo}, 6 \mathrm{mo} \\
>6 \mathrm{mo}\end{array}$ & $\begin{array}{l}\cdot \text { Weight status }{ }^{\text {a }} \\
\cdot 9-15 \text { mo of age }\end{array}$ & $\begin{array}{l}\cdot \text { Introduction to solid foods at }<4 \mathrm{mo}(\mathrm{p}=0.02), 4 \mathrm{mo} \\
(\mathrm{p}=0.008) \text { or }>6 \mathrm{mo}(\mathrm{p}=0.007), \text { compared to } 6 \mathrm{mo} \text {, associated } \\
\text { with increased odds of above normal BMI } \\
\text { [Significance for introduction to solids }<4 \mathrm{mo} \text { disappears } \\
\text { when adjusting for BF duration] }\end{array}$ \\
\hline $\begin{array}{l}\text { Zheng, } \\
\text { China, } \\
2015\end{array}$ & $\begin{array}{l}\text { Prospective } \\
\text { cohort, } \\
40510\end{array}$ & $\begin{array}{l}\text { Complementary foods } \\
<4 \mathrm{mo}, 4-6 \mathrm{mo},>6 \mathrm{mo}\end{array}$ & $\begin{array}{l}\cdot z B M I, \text { weight status } \\
\cdot 4-5 \text { years of age }\end{array}$ & $\begin{array}{l}\cdot \text { Introduction of complementary foods }<4 \text { mo associated with } \\
\text { greater } z B M I(p=<.001) \text { and higher risk of overweight } \\
(p=0.033) \text { compared to } 4-6 \mathrm{mo}\end{array}$ \\
\hline $\begin{array}{l}\text { Huh, } \\
\text { United States, } \\
2011\end{array}$ & $\begin{array}{l}\text { Prospective } \\
\text { cohort, } 847 \\
\text { [Stratified by } \\
\text { whether breastfed } \\
\text { or formula fed] }\end{array}$ & $\begin{array}{l}\text { Timing of introduction to } \\
\text { solid foods }<4 \mathrm{mo}, 4-5 \mathrm{mo} \\
>5 \mathrm{mo}\end{array}$ & $\begin{array}{l}\cdot z B M I, \text { zHeight, weight } \\
\text { status }{ }^{\text {c }} \\
\cdot 3 \text { years of age }\end{array}$ & $\begin{array}{l}\text { - Breastfed: No difference in any outcomes } \\
\text { - Formula fed: No difference in height. } \mathrm{zBMI}(\mathrm{p}=0.004) \text { and } \\
\text { odds of obesity }(\mathrm{p}<0.01) \text { higher for those introduced }<4 \mathrm{mo} \\
\text { compared to } 4-5 \mathrm{mo}\end{array}$ \\
\hline $\begin{array}{l}\text { Seach, } \\
\text { Australia, } \\
2010\end{array}$ & $\begin{array}{l}\text { Prospective } \\
\text { cohort, } 307 \\
\text { [cohort at risk of } \\
\text { developing atopy] }\end{array}$ & $\begin{array}{l}\text { Introduction to solid foods } \\
\text { measured continuously }\end{array}$ & $\begin{array}{l}\cdot \text { Weight status } \\
\cdot 10 \text { years of age }\end{array}$ & $\begin{array}{l}\text {-Delayed introduction to solid food associated with reduced } \\
\text { odds of overweight/obese }(\mathrm{p}=0.005)\end{array}$ \\
\hline \multicolumn{5}{|c|}{$\begin{array}{l}\text { a above normal BMI defined as zBMI }>2 \text { based on WHO growth standard } \\
\mathrm{b} \text { obesity defined as } \mathrm{zBMI} \geq 2 \text { and overweight defined as zBMI between } 1 \text { and } 2 \text { based on WHO growth standard } \\
{ }^{\mathrm{c}} \text { obesity defined as BMI }>95^{\text {th }} \text { percentile based on CDC growth charts }\end{array}$} \\
\hline
\end{tabular}


Appendix C: Summary of previous studies evaluating the relationship between the timing of introduction to solid food and nutrition risk

\begin{tabular}{|c|c|c|c|c|}
\hline First author, country, year & Study design, $n$ & $\begin{array}{l}\text { Independent variable or } \\
\text { exposure }\end{array}$ & $\begin{array}{l}\text { Outcome measures and age } \\
\text { of follow-up }\end{array}$ & Results \\
\hline $\begin{array}{l}\text { Hollis, } \\
\text { United Kingdom, } \\
2016\end{array}$ & $\begin{array}{l}\text { Prospective } \\
\text { cohort, } \\
2389\end{array}$ & $\begin{array}{l}\text { Timing of introduction to } \\
\text { solid food }<4 \mathrm{mo}, 4-5 \mathrm{mo} \text {, } \\
\geq 6 \mathrm{mo}\end{array}$ & $\begin{array}{l}\text { - Caregiver report of six } \\
\text { potential feeding difficulty } \\
\text { questions }{ }^{\text {a }} \\
\cdot 3 \text { years of age }\end{array}$ & $\begin{array}{l}\cdot \text { Children introduced to solids } \geq 6 \text { months had a lower risk of } \\
\text { feeding difficulties compared to introduction at } 4-5 \text { months }\end{array}$ \\
\hline $\begin{array}{l}\text { Abraham, } \\
\text { Scotland, } \\
2012\end{array}$ & $\begin{array}{l}\text { Birth cohort, } \\
5217\end{array}$ & $\begin{array}{l}\text { Timing of first } \\
\text { complementary foods } \\
0-3 \mathrm{mo}, 4-5 \mathrm{mo}, 6-10 \mathrm{mo}\end{array}$ & $\begin{array}{l}\text { - Cluster analysis to group } \\
\text { children with similar eating } \\
\text { patterns }{ }^{\text {b }} \\
\text {-2 years }\end{array}$ & $\begin{array}{l}\text { - Children who started complementary feeding at } 4-5 \text { months } \\
\text { or } 6-10 \text { months, compared to } 0-3 \text { months, were part of a } \\
\text { cluster with a more positive eating pattern (e.g. higher } \\
\text { fruit/vegetable intake, less sweets, etc.) }\end{array}$ \\
\hline $\begin{array}{l}\text { Northstone/Coulthard, } \\
\text { United Kingdom, } \\
\text { 2001/2009 }\end{array}$ & $\begin{array}{l}\text { Longitudinal } \\
\text { study, } \\
7821\end{array}$ & $\begin{array}{l}\text { Timing of introduction to } \\
\text { lumpy solids }<6 \mathrm{mo}, 6- \\
9 \mathrm{mo},>9 \mathrm{mo}\end{array}$ & $\begin{array}{l}\text { - Caregiver report of six } \\
\text { potential feeding difficulty } \\
\text { questions }{ }^{\text {a }} \\
\cdot 6 \mathrm{mo}, 15 \mathrm{mo}, 7 \text { years of age }\end{array}$ & $\begin{array}{l}\text {-Introduction to lumpy solids } \geq 10 \text { months compared to } 6-9 \\
\text { months ate less variety and had increased feeding difficulties } \\
\text { at } 6 \text { months, } 15 \text { months and } 7 \text { years }\end{array}$ \\
\hline \multicolumn{5}{|c|}{$\begin{array}{l}\text { a This tool was developed for the Avon Longitudinal Study of Parents and Children (ALSPAC). Caregivers were asked how worried they were about the following: (1) } \\
\text { whether they felt there had been difficulties feeding their child; (2) not eating sufficient amounts of food; (3) refusal to eat the right food; (4) being choosy with food; (5) } \\
\text { over-eating; (6) being difficult to get into a feeding routine. }\end{array}$} \\
\hline
\end{tabular}


Appendix D: Nutrition and Health Questionnaire (NHQ) provided to child's caregiver to determine time introduced to infant cereal

29. At what age did you introduce:
a) Infant cereal
Age introduced
months OR
b) Cows milk
Age introduced
months
OR $\square$ Not yet introduced
c) Juice
Age introduced
months OR $\square$ Not yet introduced 


\section{Nutrition Screening Tool for Every Preschooler}

\section{Instructions}

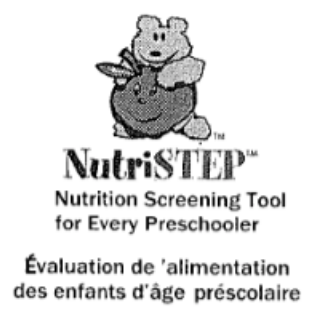

- Below are questions about your preschool child's (3 to 5 year old) eating and other habits.

- Think about your child's every day habits when answering. Check $(\sqrt{ })$ only one answer for each question.

- There is a number from 0 to 4 beside each answer. This number is a score for that question. At the bottom of each page is a box for the score for the page. For each page, add up the scores for each question.

- At the end of the questionnaire, you will add the page scores to get the total score.

1. My child usually eats grain products:

Examples are bread, bagel, bun, cereal, pasta, rice, roti and tortillas.

$\square$ More than 5 times a day

, $\square \quad 4$ to 5 times a day

${ }_{2} \square \quad 2$ to 3 times a day

${ }_{4} \square \quad$ Less than 2 times a day

2. My child usually has milk products:

Examples are white or chocolate milk, cheese, yogurt, milk puddings or milk substitutes such as fortified soy beverages.

$\square$ More than 3 times a day

, 3 times a day

${ }_{2} \square \quad 2$ times a day

${ }_{4} \square \quad$ Once a day or less

3. My child usually eats fruit:

0 More than 3 times a day

, $\square$ times a day

${ }_{2} \square \quad 2$ times a day

${ }_{3} \square$ Once a day

${ }_{4} \square \quad$ Not at all

\section{Total Score for Page 1}

Copyright (c) 2007 Sudbury \& District Health Unit, Janis Randall Simpson and Heather Keller. NutriSTEP is the copyright of the Sudbury \& District Health Unit, Janis Randall Simpson and Heather Keller and must not be used, copied or distributed without a license from the University of Guelph. The Sudbury \& District Health Unit is the owner of trademarks used throughout. For more information, visit: [http://www. flintbox.com]. 
4. My child usually eats vegetables:

0 $\square$ More than 2 times a day

, $\square$ times a day

${ }_{3} \square \quad$ Once a day

${ }_{4} \square \quad$ Not at all

5. My child usually eats meat, fish, poultry or alternatives:

Alternatives can be eggs, peanut butter, tofu, nuts, or dried beans, peas and lentils.

0 $\square$ More than 2 times a day

, $\square \quad 2$ times a day

${ }_{2} \square \quad$ Once a day

${ }_{3} \square \quad$ A few times a week

${ }_{4} \square \quad$ Not at all

6. My child usually eats "fast food":

${ }_{4} \square \quad 4$ or more times a week

${ }_{3} \square \quad 2$ to 3 times a week

${ }_{2} \square \quad$ Once a week

, $\square \quad$ A few times a month

${ }_{0} \square \quad$ Once a month or less

7. I have difficulty buying food to feed my child because food is expensive:

${ }_{4} \square \quad$ Most of the time

${ }_{2} \square$ Sometimes

,$\square$ Rarely

${ }_{0} \square$ Never

8. My child has problems chewing, swallowing, gagging or choking when eating:

${ }_{4} \square \quad$ Most of the time

${ }_{2} \square$ Sometimes

$1 \square$ Rarely

${ }_{0} \square \quad$ Never

9. My child is not hungry at mealtimes because he/she drinks all day:

${ }_{4} \square \quad$ Most of the time

${ }_{2} \square$ Sometimes

,$\square$ Rarely

${ }_{0} \square$ Never

\section{Total Score for Page 2}

Copyright (c) 2007 Sudbury \& District Health Unit, Janis Randall Simpson and Heather Keller. NutriSTEP is the copyright of the Sudbury \& District Health Unit, Janis Randall Simpson and Heather Keller and must not be used, copied or distributed without a license from the University of Guelph. The Sudbury \& District Health Unit is the owner of trademarks used throughout. For more information, visit: [http://www.flintbox.com]. 
10. My child usually eats:

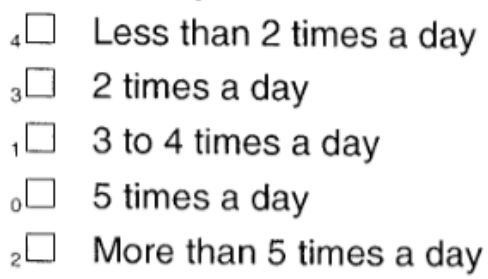

11. I let my child decide how much to eat:
$0 \quad$ Always
${ }_{1} \square$ Most of the time
${ }_{2} \square$ Sometimes
${ }_{3} \square$ Rarely
${ }_{4} \square$ Never

12. My child eats meals while watching TV:

${ }_{4} \square \quad$ Always
${ }_{3} \square \quad$ Most of the time
${ }_{2} \square \quad$ Sometimes
${ }_{1} \square \quad$ Rarely
${ }_{0} \square \quad$ Never

13. My child usually takes supplements:

Examples are multivitamins, iron drops, cod liver oil.

${ }_{4} \square \quad$ Always
${ }_{3} \square \quad$ Most of the time
${ }_{2} \square \quad$ Sometimes
${ }_{1} \square \quad$ Rarely
${ }_{0} \square \quad$ Never

14. My child:
${ }_{4} \square \quad$ Needs more physical activity
$0 \quad$ Gets enough physical activity

15. My child usually watches TV, uses the computer, and plays video games:

${ }_{4} \square \quad 5$ or more hours a day

${ }_{3} \square \quad 4$ hours a day

${ }_{2} \square \quad 3$ hours a day

, $\square 2$ hours a day

${ }_{0} \square \quad 1$ hour or less a day

\section{Total Score for Page 3}

Copyright (c) 2007 Sudbury \& District Health Unit, Janis Randall Simpson and Heather Keller. NutriSTEP is the copyright of the Sudbury \& Distric Health Unit, Janis Randall Simpson and Heather Keller and must not be used, copied or distributed without a license from the University of Guelph. The Sudbury \& District Health Unit is the owner of trademarks used throughout. For more information, visit: [http://www.flintbox.com]. 
16. I am comfortable with how my child is growing:

$\square$ Yes

${ }_{4} \square \quad$ No

17. My child:

${ }_{4} \square$ Should weigh more

${ }_{0} \square \quad$ Is about the right weight

${ }_{2} \square$ Should weigh less

Total Score for Page 4

\section{To get a total score, add the scores for each page.}

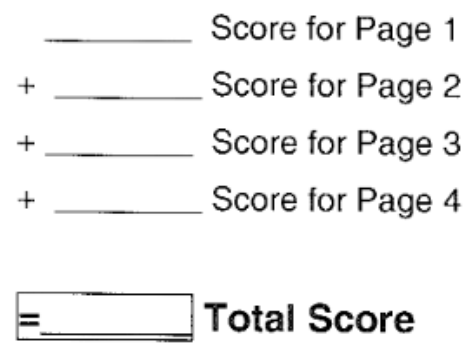

\section{What does your NutriSTEPTM score mean?}

If the total score is 20 or less:

Your child's eating and activity habits are good. There may be things that you want to work on; check out the educational material provided for tips and more information.

If the total score is 21 to 25 :

Your child's eating and activity habits can be improved by making some small changes. Check out the educational material provided or [insert local contact information] for tips and more information.

If the total score is 26 and greater:

Your child's eating and activity habits can be improved by making some changes. For suggestions, talk to a health professional such as a registered dietitian, your family doctor or paediatrician or [insert local contact information].

Copyright (c) 2007 Sudbury \& District Health Unit, Janis Randall Simpson and Heather Keller. NutriSTEP is the copyright of the Sudbury \& District Health Unit, Janis Randall Simpson and Heather Keller and must not be used, copied or distributed without a license from the University of Guelph. The Sudbury \& District Health Unit is the owner of trademarks used throughout. For more information, visit: [http://www.flintbox.com] 
Appendix F: Data creation plan for original research study

\section{TARGet Kids! Dataset Creation and Analysis Plan (DCP)}

\begin{tabular}{lcl}
\hline \hline Name of Study & Timing of introduction to solid food, growth and nutrition risk in later childhood \\
\hline PI and P\&B Contacts & $\bullet \quad$ Jonathon Maguire \\
& $\bullet \quad$ Curtis D'Hollander \\
\hline
\end{tabular}

Primary Research Question:

1. Is later introduction to solid food (i.e. at 6 months) associated with lower body mass index z-score in later childhood?

Hypothesis

1. Introduction to solid food at 6 months, compared to 4 or 5 months, will be associated with lower body mass index z-score in later childhood.

Any secondary questions or secondary outcomes:

Research Question and hypothesis
1. Is later introduction to solid food (i.e. at 6 months) associated with higher height in later childhood?

2. Is later introduction to solid food (i.e. at 6 months) associated with improved nutrition risk in later childhood?

3. Are the aforementioned relationships modified by breast/formula feeding or child age?

Hypotheses

1. Introduction to solid food at 6 months, compared to 4 or 5 months, will be associated with higher height for age z-score in later childhood.

2. Introduction to solid food at 6 months, compared to 4 or 5 months, will be associated with improved nutrition risk in later childhood.

3. A. Infants breastfed prior to the introduction of solid food will have lower body mass index z-score, greater height and improved nutrition risk, compared with those who were fully or partially formula fed.

B. The relationships will vary with child age.

Defining the Cohort

TARGet Kids! Children recruited between ages 0 to 5 years and followed prospectively at well-child visits from Cohort primary care pediatrician's or family physician's office affiliated with the TARGet Kids research network.

Exclusions $\quad$ - Children with associated health conditions affecting growth (e.g. failure to thrive, cystic fibrosis)

- Children with any chronic condition(s) except for asthma

- Children with severe developmental delay

- $<32$ weeks' gestation

- Never introduced to infant cereal

Study Design $\triangle$ Cohort - longitudinal using repeated measures of outcomes up to 10 years of age. 


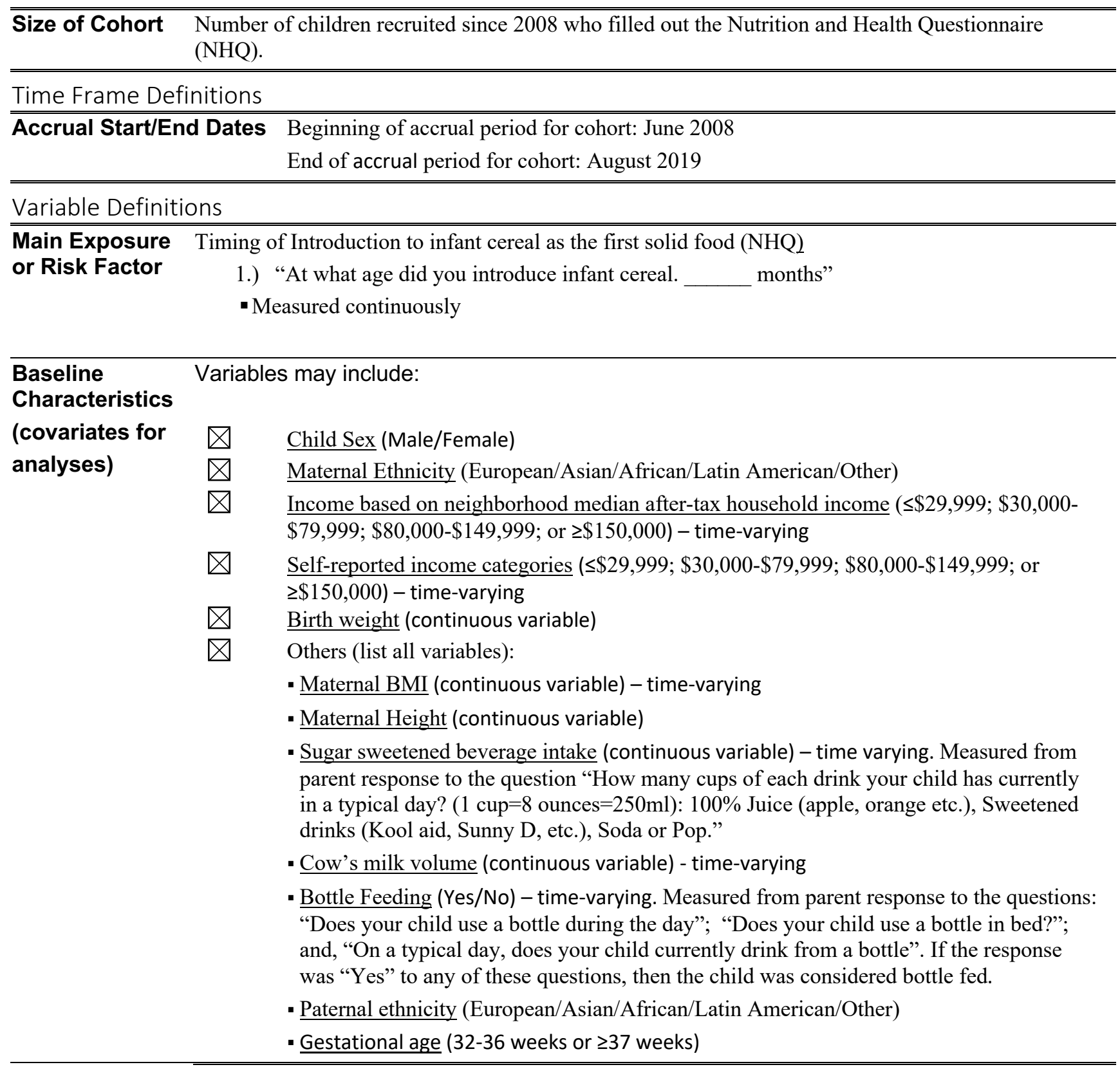

\section{Outcome}

Definition(s)

Primary Outcome:

- Body Mass Index z-score (continuous variable) - time-varying

\section{Secondary Outcomes:}

- Weight status categories

○ Under weight (zBMI $<-2)$

- Normal weight $(-2 \leq \mathrm{zBMI} \leq 1)$ [reference]

- Overweight $(1<\mathrm{zBMI} \leq 2)$

$\circ$ Obese (zBMI $>2)$

- Height for age z-score (continuous variable) - time-varying 
- Nutrition Screening Tool for Toddler and Preschoolers (NutriSTEP) total score (continuous variable) - time-varying

- NutriSTEP dietary intake sub-score (continuous variable) - time-varying

- NutriSTEP eating behaviour sub-score (continuous variable) - time-varying

\section{Effect modifiers:}

- Child age (continuous) - time-varying

- Note: this is the age of the child at the time of the primary or secondary outcome measurement

- Feeding type in the first year of life

- My child received infant formula $80-100 \%$ of the time (was exclusively formula fed

○ My child received breast milk $80-100 \%$ of the time (was exclusively breastfed)

$\circ \quad$ My child received both breast milk and formula equally

\section{Depiction of when outcome measurements are collected in longitudinal cohort study}

- Nutrition risk (NutriSTEP) measures collected repeatedly between 18 months and 5 years of age

- Growth measures (zBMI and zHeight) collected repeatedly between 0 and 10 years of age

$\circ \quad$ The triangles represent (hypothetical) data collection times for children introduced to solid foods at $\mathrm{x}$ and $\mathrm{y}$ months

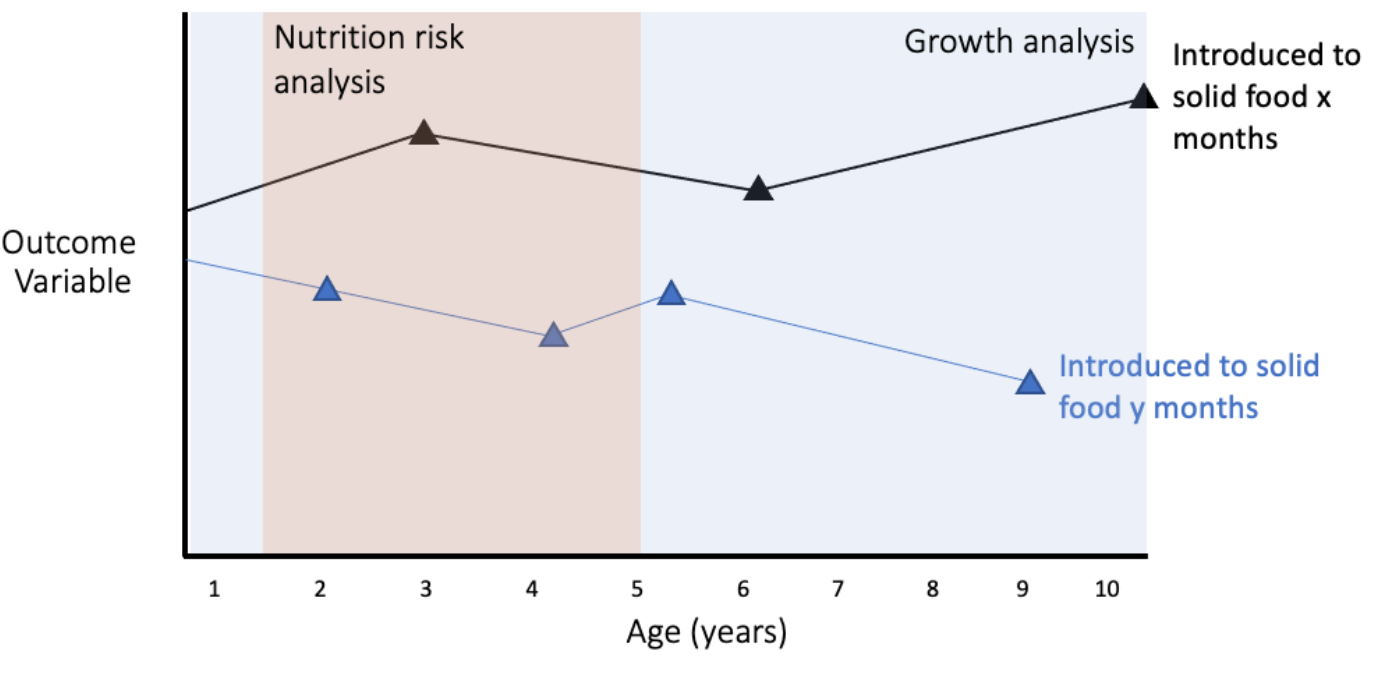


Analysis Plan

1. Descriptive analysis

- Baseline primary exposure, outcomes and covariates

2. Missing data

- Data assumed to be missing at random

- Multiple imputation with 20 data sets including exposure, outcomes and covariates

\section{Non-linearity and effect modification}

- Models will include non-linearity based on a priori knowledge using restricted cubic splines (5 knots) placed at the quantiles - pairwise comparisons will be used to compare introduction to infant cereal at 6 months [reference] vs. 5 and 4 months for each of the outcomes.

- Interaction terms will be included if likelihood ratio results are $\mathrm{p}<0.30$.

\section{Primary analysis}

- Linear mixed effect modelling for analyzing zBMI continuously

\section{Secondary analysis}

- Linear mixed effect model for analyzing zHeight and NutriSTEP outcomes continuously

- Generalized estimating equations for analyzing weight status categories 


\section{CHAPTER 7: REFERENCES}

1. World Health Organization. The Importance of Infant and Young Child Feeding and Recommended Practices. Geneva; 2009.

https://www.ncbi.nlm.nih.gov/books/NBK148967/. Accessed January 10, 2021.

2. Robinson SM. Infant nutrition and lifelong health: Current perspectives and future challenges. J Dev Orig Health Dis. 2015;6(5):384-389. doi:10.1017/S2040174415001257

3. Plagemann A, Harder T, Schellong K, Schulz S, Stupin JH. Early postnatal life as a critical time window for determination of long-term metabolic health. Best Pract Res Clin Endocrinol Metab. 2012;26(5):641-653. doi:10.1016/j.beem.2012.03.008

4. World Health Organization. Infant and young child feeding. https://www.who.int/newsroom/fact-sheets/detail/infant-and-young-child-feeding. Published April 1, 2020.

Accessed July 8, 2020.

5. Fewtrell M, Bronsky J, Campoy C, et al. Complementary feeding: A position paper by the European Society for Paediatric Gastroenterology, Hepatology, and Nutrition (ESPGHAN) committee on nutrition. J Pediatr Gastroenterol Nutr. 2017;64(1):119-132. doi:10.1097/MPG.0000000000001454

6. Health Canada, Canadian Paediatric Society, Dietitians of Canada, Breastfeeding Committe for Canada. Nutrition for Healthy Term Infants: Recommendations from Birth to Six Months. https://www.canada.ca/en/health-canada/services/canada-foodguide/resources/infant-feeding/nutrition-healthy-term-infants-recommendations-birth-sixmonths.html. Published 2012. Accessed July 8, 2020.

7. Centers for Disease Control and Prevention. When, What, and How to Introduce Solid Foods. https://www.cdc.gov/nutrition/infantandtoddlernutrition/foods-and-drinks/when-tointroduce-solid-foods.html. Published 2019. Accessed July 8, 2020.

8. United Kingdom National Health Service: Your pregnancy and baby guide. Your baby's first solid foods. https://www.nhs.uk/conditions/pregnancy-and-baby/solid-foodsweaning/. Published 2019. Accessed July 8, 2020.

9. Swedish National Food Agency. Good food for infants under one year. https://www.livsmedelsverket.se/globalassets/publikationsdatabas/andra-sprak/bra-matfor-spadbarn/good-food-for-infants-under-one-year-livsmedelsverket.pdf. Published 2012. Accessed July 8, 2020.

10. Nederlands Centrim Jeugdgezondheid. Guidelines: Nutrition and eating behaviour (2013, adaptation 2017). https://www.ncj.nl/richtlijnen/allerichtlijnen/richtlijn/?richtlijn=4\&rlpag=526. Published 2017. Accessed July 8, 2020.

11. Brophy S, Cooksey R, Gravenor MB, et al. Risk factors for childhood obesity at age 5: Analysis of the Millennium Cohort study. BMC Public Health. 2009;9:1-7. doi:10.1186/1471-2458-9-467

12. Sun C, Foskey RJ, Allen KJ, et al. The Impact of Timing of Introduction of Solids on Infant Body Mass Index. J Pediatr. 2016;179:104-110.e1.

doi:10.1016/j.jpeds.2016.08.064

13. Abraham EC, Godwin J, Sherriff A, Armstrong J. Infant feeding in relation to eating patterns in the second year of life and weight status in the fourth year. Public Health Nutr. 2012;15(9):1705-1714. doi:10.1017/S1368980012002686

14. English LK, Obbagy JE, Wong YP, et al. Timing of introduction of complementary foods and beverages and growth, size, and body composition: a systematic review. Am J Clin 
Nutr. 2019;109(7):935S-955S. doi:10.1093/ajcn/nqy267

15. Public Health Agency of Canada. Stages of childhood. https://www.canada.ca/en/publichealth/services/health-promotion/childhood-adolescence/stages-childhood/infancy-birthtwo-years.html. Published 2016. Accessed March 27, 2021.

16. Scharf RJ, Scharf GJ, Stroustrup A. Developmental Milestones. Pediatr Rev. 2016;37(1):25-37. doi:10.1542/pir.2014-0103

17. SickKids Staff. Growth in the first year. 2009. https://www.aboutkidshealth.ca/Article?contentid=482\&language=English. Accessed January 22, 2021.

18. Schwarzenberg SJ, Georgieff MK. Advocacy for improving nutrition in the first 1000 days to support childhood development and adult health. Pediatrics. 2018;141(2). doi:10.1542/peds.2017-3716

19. Brands B, Demmelmair H, Koletzko B. How growth due to infant nutrition influences obesity and later disease risk. Acta Paediatr. 2014;103(6):578-585.

doi:10.1111/apa. 12593

20. Weng SF, Redsell SA, Swift JA, Yang M, Glazebrook CP. Systematic review and metaanalyses of risk factors for childhood overweight identifiable during infancy. Arch Dis Child. 2012;97(12):1019-1026. doi:10.1136/archdischild-2012-302263

21. Bhadoria A, Sahoo K, Sahoo B, Choudhury A, Sufi N, Kumar R. Childhood obesity: Causes and consequences. J Fam Med Prim Care. 2015;4(2):187. doi:10.4103/22494863.154628

22. Paajanen TA, Oksala NKJ, Kuukasjärvi P, Karhunen PJ. Short stature is associated with coronary heart disease: A systematic review of the literature and a meta-analysis. Eur Heart J. 2010;31(14):1802-1809. doi:10.1093/eurheartj/ehq155

23. Deaton A, Arora R. Life at the top: The benefits of height. Econ Hum Biol. 2009;7(2):133136. doi:10.1016/j.ehb.2009.06.001

24. Case A, Paxson C. Height, health, and cognitive function at older ages. Am Econ Rev. 2008;98(2):463-467. doi:10.1257/aer.98.2.463

25. Perkins JM, Subramanian S V., Smith GD, Özaltin E. Adult height, nutrition, and population health. Nutr Rev. 2016;74(3):149-165. doi:10.1093/nutrit/nuv105

26. Birch LL. Development of food preferences. Anпu Rev Nutr. 1999;19:41-62. doi:10.1146/annurev.nutr.19.1.41

27. Mennella JA, Nicklaus S, Jagolino AL, Yourshaw LM. Variety is the spice of life: Strategies for promoting fruit and vegetable acceptance during infancy. Physiol Behav. 2008;94(1):29-38. doi:10.1016/j.physbeh.2007.11.014

28. Coulthard H, Harris G, Emmett P. Long-term consequences of early fruit and vegetable feeding practices in the United Kingdom. Public Health Nutr. 2010;13(12):2044-2051. doi: $10.1017 /$ S1368980010000790

29. Fisher J, Birch L. Fat preferences and fat consumption of 3- to 5-year-old children are related to parental adiposity. J Am Diet Assoc. 1995;95(7):759-764. doi:10.1016/S00028223(95)00212-X

30. Institute of Medicine. Dietary Reference Intakes Research Synthesis: Workshop Summary. Washington (DC): The National Academies Press; 2007. doi:https://doi.org/10.17226/11767

31. Health Canada. Dietary Reference Intakes. https://www.canada.ca/content/dam/hcsc/migration/hc-sc/fn-an/alt_formats/hpfb-dgpsa/pdf/nutrition/dri_tables-eng.pdf. 
Published 2010.

32. Robinson SM, Marriott LD, Crozier SR, et al. Variations in infant feeding practice are associated with body composition in childhood: A prospective cohort study. J Clin Endocrinol Metab. 2009;94(8):2799-2805. doi:10.1210/jc.2009-0030

33. Hermoso M, Tabacchi G, Iglesia-Altaba I, et al. The nutritional requirements of infants. Towards EU alignment of reference values: the EURRECA network. Matern Child Nutr. 2010;6(Suppl. 2):55-83. doi:10.1111/j.1740-8709.2010.00262.x

34. Martin CR, Ling PR, Blackburn GL. Review of infant feeding: Key features of breast milk and infant formula. Nutrients. 2016;8(5):1-11. doi:10.3390/nu8050279

35. $\mathrm{Ng}$ E, Loewy AD. Guidelines for Vitamin K prophylaxis in newborns. Paediatr Child Heal. 2018;23(6):394-397. doi:10.1093/pch/pxy082

36. Health Canada, Canadian Paediatric Society, Dietitians of Canada, Breastfeeding Committee of Canada. Nutrition for Healthy Term Infants: Recommendations from Six to 24 Months. https://www.canada.ca/en/health-canada/services/canada-foodguide/resources/infant-feeding/nutrition-healthy-term-infants-recommendations-birth-sixmonths/6-24-months.html. Published 2014. Accessed September 30, 2020.

37. Pound CM, Unger SL. The baby-friendly Initiative: Protecting, promoting and supporting breastfeeding. Paediatr Child Health (Oxford). 2012;17(6):317-321.

doi:10.1093/pch/17.6.317

38. Section on Breastfeeding. Breastfeeding and the use of human milk. Pediatrics. 2012;129(3):e827-e841. doi:10.1542/peds.2011-3552

39. Stough CO, Khalsa AS, Nabors LA, Merianos AL, Peugh J. Predictors of Exclusive Breastfeeding for 6 Months in a National Sample of US Children. Am J Heal Promot. 2019;33(1):48-56. doi:10.1177/0890117118774208

40. Institute of Medicine (US) Committee on the Evaluation of the Addition of Ingredients New to Infant Formula. Infant Formula: Evaluating the Safety of New Ingredients. Chapter 3. Washington (DC): National Academies Press (US); 2004.

41. National Health and Medical Research Council. Infant Feeding Guidelines. Canberra: NHMRC; 2012. https://www.nhmrc.gov.au/about-us/publications/infant-feedingguidelines-information-health-workers.

42. Nestle. Good Start Plus 1 Baby Formula, Powder. https://www.nestlebaby.ca/en/goodstart-plus-1. Accessed January 24, 2021.

43. Ziegler EE. Growth of Breast-Fed and Formula-Fed Infants. Nestlé Nutr Work Ser Pediatr Progr. 2006;58:51-63. doi:10.1159/000095010

44. Yan J, Liu L, Zhu Y, Huang G, Wang PP. The association between breastfeeding and childhood obesity: A meta-analysis. World Rev Nutr Diet. 2014;114:110-111. doi:10.1159/000441820

45. Specht IO, Rohde JF, Olsen NJ, Heitmann BL. Duration of exclusive breastfeeding may be related to eating behaviour and dietary intake in obesity prone normal weight young children. PLoS One. 2018;13(7):1-11. doi:10.1371/journal.pone.0200388

46. Perrine CG, Galuska DA, Thompson FE, Scanlon KS. Breastfeeding duration is associated with child diet at 6 years. Pediatrics. 2014;134:S50-S55. doi:10.1542/peds.2014-0646I

47. Scott JA, Chih TY, Oddy WH. Food variety at 2 years of age is related to duration of breastfeeding. Nutrients. 2012;4(10):1464-1474. doi:10.3390/nu4101464

48. Ball TM, Wright AL. Health care costs of formula-feeding in the first year of life. 
Pediatrics. 1999;103(4 part 2):870-876.

49. Steube A. The risks of not breastfeeding for mothers and infants. Rev Obstet Gynecol. 2009;2(4):222-231. doi:10.3909/riog0093

50. Victora CG, Bahl R, Barros AJD, et al. Breastfeeding in the 21st century: Epidemiology, mechanisms, and lifelong effect. Lancet. 2016;387(10017):475-490. doi:10.1016/S01406736(15)01024-7

51. Marchand V. Promoting optimal monitoring of child growth in Canada: using the new World Health Organization growth charts. Paediatr Child Heal. 2010;15(2):77-79. www.dietitians.ca/growthcharts. Accessed February 6, 2021.

52. Horan M, Gibney E, Molloy E, McAuliffe F. Methodologies to assess paediatric adiposity. Ir J Med Sci. 2015;184(1):53-68. doi:10.1007/s11845-014-1124-1

53. Martin-Calvo N, Moreno-Galarraga L, Martinez-Gonzalez MA. Association between body mass index, waist-to-height ratio and adiposity in children: A systematic review and meta-analysis. Nutrients. 2016;8(8):512. doi:10.3390/nu8080512

54. Lindsay RS, Hanson RL, Roumain J, Ravussin E, Knowler WC, Tataranni PA. Body Mass Index as a Measure of Adiposity in Children and Adolescents: Relationship to Adiposity by Dual Energy X-Ray Absorptiometry and to Cardiovascular Risk Factors. $J$ Clin Endocrinol Metab. 2001;86(9):4061-4067. doi:10.1210/jcem.86.9.7760

55. Simmonds M, Burch J, Llewellyn A, et al. The use of measures of obesity in childhood for predicting obesity and the development of obesity-related diseases in adulthood: a systematic review and meta-analysis. Health Technol Assess (Rockv). 2015;19(43):Chapter 1. doi:10.3310/hta19430

56. Cole TJ. The development of growth references and growth charts. Ann Hum Biol. 2012;39(5):382-394. doi:10.3109/03014460.2012.694475

57. World Health Organization. WHO Child Growth Standards: Methods and Development.; 2006. https://www.who.int/childgrowth/standards/Technical_report.pdf?ua=1. Accessed July 8, 2020.

58. De Onis M, Onyango AW, Borghi E, Siyam A, Nishida C, Siekmann J. Development of a WHO growth reference for school-aged children and adolescents. Bull World Health Organ. 2007;85(9):660-667. doi:10.2471/BLT.07.043497

59. Wang Y, Chen H-J. Use of Percentiles and Z-Scores in Anthropometry. New York, NY: Springer; 2012. doi:10.1007/978-1-4419-1788-1_2

60. Dietitians of Canada and the Canadian Paediatric Society. A Health Professional's Guide for Using the WHO Growth Charts for Canada.; 2014.

https://www.dietitians.ca/DietitiansOfCanada/media/Documents/WHO Growth Charts/2014-A-Health-Professionals-Guide-to-Using-the-Charts.pdf. Accessed February 22, 2021.

61. Kuczmarski RJ, Ogden CL, Grummer-Strawn LM, et al. CDC growth charts: United States. Adv Data. 2000;314:1-27. http://www.cdc.gov/growthcharts. Accessed February 22, 2021.

62. Centers for Disease Control and Prevention. Use of World Health Organization and CDC Growth Charts for Children Aged 0-59 Months in the United States. Morb Mortal Wkly Rep. 2010;59(RR-9).

63. Haschke F, van't Hof MA. Euro-Growth References for Length, Weight, and Body Circumferences. Euro-Growth Study Group. J Pediatr Gastroenterol Nutr. 2000;31(1):S14-S38. 
64. Turck D, Michaelsen KF, Shamir R, et al. World Health Organization 2006 child growth standards and 2007 growth reference charts: A discussion paper by the committee on nutrition of the European society for pediatric gastroenterology, hepatology, and nutrition. J Pediatr Gastroenterol Nutr. 2013;57(2):258-264. doi:10.1097/MPG.0b013e318298003f

65. Statistics Canada. Overweight and obese adults, 2018. www.statcan.gc.ca. Published 2018. Accessed February 6, 2021.

66. Bancej C, Jayabalasingham B, Wall RW, et al. Trends and projections of obesity among Canadians. Res Policy Pract. 2015;35(7):109-112. doi:10.24095/hpcdp.35.7.02

67. Rao D, Kropac E, Do M, Roberts K, Jayaraman G. Childhood overweight and obesity trends in Canada. Res Policy Pract. 2016;36(9).

68. Bentham J, Di Cesare M, Bilano V, et al. Worldwide trends in body-mass index, underweight, overweight, and obesity from 1975 to 2016: a pooled analysis of 2416 population-based measurement studies in 128.9 million children, adolescents, and adults. Lancet. 2017;390(10113):2627-2642. doi:10.1016/S0140-6736(17)32129-3

69. Jelenkovic A, Sund R, Hur YM, et al. Genetic and environmental influences on height from infancy to early adulthood: An individual-based pooled analysis of 45 twin cohorts. Sci Rep. 2016;6(1):1-13. doi:10.1038/srep28496

70. Silventoinen K. Determinants of variation in adult body height. J Biosoc Sci. 2003;35(2):263-285. doi:10.1017/S0021932003002633

71. Addo OY, Stein AD, Fall CH, et al. Maternal height and child growth patterns. J Pediatr. 2013;163(2):549-554. doi:10.1016/j.jpeds.2013.02.002

72. Herzog D, Fournier N, Buehr P, et al. Early-onset Crohn's disease is a risk factor for smaller final height. Eur J Gastroenterol Hepatol. 2014;26(11):1234-1239. doi:10.1097/MEG.0000000000000169

73. Hwang AE, MacK TM, Hamilton AS, et al. Childhood infections and adult height in monozygotic twin pairs. Am J Epidemiol. 2013;178(4):551-558. doi:10.1093/aje/kwt012

74. Grasgruber P, Cacek J, Kalina T, Sebera M. The role of nutrition and genetics as key determinants of the positive height trend. Econ Hum Biol. 2014;15:81-100. doi:10.1016/j.ehb.2014.07.002

75. Naylor AJ, Morrow AL. Developmental Readiness of Normal Full Term Infants to Progress from Exclusive Breastfeeding to the Introduction of Complementary Foods: Reviews of the Relevant Literature Concerning Infant Immunologic, Gastrointestinal, Oral Motor and Maternal Reproducti. Washington (DC): Wellstart International; 2001.

76. WHO. The World Health Organization's infant- feeding recommendation. Wkly Epidemiol Rec. 1995;70:119-120.

77. Lanigan JA, Bishop JA, Kimber AC, Morgan J. Systematic review concerning the age of introduction of complementary foods to the healthy full-term infant. Eur J Clin Nutr. 2001;55(5):309-320. doi:10.1038/sj.ejcn.1601168

78. WHO. Global Strategy for Infant and Young Child Feeding. The Optimal Duration of Exclusive Breastfeeding. Geneva; 2001. https://apps.who.int/iris/bitstream/handle/10665/78801/ea54id4.pdf?sequence=1. Accessed February 16, 2021.

79. Kramer MS, Kakuma R. The Optimal Duration of Exclusive Breastfeeding: A Systematic Review. Geneva; 2002.

https://www.who.int/nutrition/publications/optimal_duration_of_exc_bfeeding_review_en g.pdf. Accessed February 16, 2021. 
80. Kramer MS, Chalmers B, Hodnett ED, et al. Promotion of breastfeeding intervation trial (PROBIT): A randomized trial in the Republic of Belarus. J Am Med Assoc. 2001;285(4):413-420. doi:10.1001/jama.285.4.413

81. Kramer M, Kakuma R. Optimal duration of exclusive breastfeeding. Cochrane Database Syst Rev. 2012;(8):CD003517.

doi:10.1002/14651858.CD003517.pub2.www.cochranelibrary.com

82. Khadivzadeh T, Parsai S. Effect of exclusive breastfeeding and complementary feeding on infant growth and morbidity. East Mediterr Heal J. 2004;10(3):289-294.

83. Onayade AA, Abiona TC, Abayomi IO, Makanjuola ROA. The first six month growth and illness of exclusively and non-exclusively breast-fed infants in Nigeria. East Afr Med J. 2004;81(3):146-153. doi:10.4314/eamj.v81i3.9145

84. World Health Organization. Call for authors - Systematic reviews on feeding of infants and young children 6-23 months of age. https://www.who.int/news-room/articlesdetail/call-for-authors-systematic-reviews-on-feeding-of-infants-and-young-children-623months. Published 2020. Accessed March 27, 2021.

85. Australian Government Department of Health. Introducing Solids; 2011. https:/www1.health.gov.au/internet/publications/publishing.nsf/Content/gug-directortoc $\sim$ gug-solids\#: :text=Around six months of age,baby's system is still immature.

86. Canadian Paediatric Society. Nutrition for healthy term infants. Paediatr Child Heal. 1998;3(2):97-101.

87. Boland M. Exclusive breastfeeding should continue to six months. Paediatr Child Health (Oxford). 2005;10(3):148. doi:10.1093/pch/10.3.148

88. Critch JN, Society CP, Committee N and G. Nutrition for healthy term infants, birth to six months: An overview. Paediatr Child Health. 2013;18(4):206-207. doi:10.1093/pch/18.4.206

89. Haiek LN, Gauthier DL, Brosseau D, Rocheleau L. Understanding breastfeeding behavior: Rates and shifts in patterns in Québec. J Hum Lact. 2007;23(1):24-31. doi:10.1177/0890334406297278

90. Gionet L. Breastfeeding trends in Canada. Statistics Canada Catalogue no. 82-624-X. https://www150.statcan.gc.ca/n1/pub/82-624-x/2013001/article/11879-eng.htm. Published 2013. Accessed February 17, 2021.

91. Clayton HB, Li R, Perrine CG, Scanlon KS. Prevalence and reasons for introducing infants early to solid foods: Variations by milk feeding type. Pediatrics. 2013;131(4):e1108. doi:10.1542/peds.2012-2265

92. Schiess S, Grote V, Scaglioni S, et al. Introduction of Complementary Feeding in 5 European Countries. J Pediatr Gastroenterol Nutr. 2010;50(1):92-98. doi:10.1097/MPG.0b013e31819f1ddc

93. Samady W, Campbell E, Aktas ON, et al. Recommendations on Complementary Food Introduction Among Pediatric Practitioners. JAMA Netw open. 2020;3(8):e2013070. doi:10.1001/jamanetworkopen.2020.13070

94. Kronborg H, Foverskov E, Væth M. Predictors for early introduction of solid food among Danish mothers and infants: An observational study. BMC Pediatr. 2014;14(1). doi:10.1186/1471-2431-14-243

95. Friel JK, Hanning RM, Isaak CA, Prowse D, Miller AC. Canadian infants' nutrient intakes from complementary foods during the first year of life. BMC Pediatr. 2010;10.

doi:10.1186/1471-2431-10-43 
96. Roess AA, Jacquier EF, Catellier DJ, et al. Food consumption patterns of infants and toddlers: Findings from the feeding infants and toddlers study (FITS) 2016. J Nutr. 2018;148(9):1525S-1535S. doi:10.1093/jn/nxy171

97. Lange C, Visalli M, Jacob S, Chabanet C, Schlich P, Nicklaus S. Maternal feeding practices during the first year and their impact on infants' acceptance of complementary food. Food Qual Prefer. 2013;29(2):89-98. doi:10.1016/j.foodqual.2013.03.005

98. Yu C, Binns CW, Lee AH. The early introduction of complementary (Solid) foods: A prospective cohort study of infants in chengdu, china. Nutrients. 2019;11(4):760. doi:10.3390/nu11040760

99. Klerks M, Bernal MJ, Roman S, Bodenstab S, Gil A, Sanchez-Siles LM. Infant cereals: Current status, challenges, and future opportunities for whole grains. Nutrients. 2019;11(2):473. doi:10.3390/nu11020473

100. A Nicklas T, E O'Neil C, L Fulgoni III V. Nutrient intake, introduction of baby cereals and other complementary foods in the diets of infants and toddlers from birth to 23 months of age. AIMS Public Heal. 2020;7(1):231-147. doi:10.3934/publichealth.2020012

101. Anderson LN, van den Heuvel M, Omand JA, Wong PD. Practical tips for paediatricians: Baby-led weaning. Paediatr Child Health. 2020;25(2):77-78.

102. Taylor RW, Williams SM, Fangupo LJ, et al. Effect of a baby-led approach to complementary feeding on infant growth and overweight: A randomized clinical trial. JAMA Pediatr. 2017;171(9):838-846. doi:10.1001/jamapediatrics.2017.1284

103. Brown A, Jones SW, Rowan H. Baby-Led Weaning: The Evidence to Date. Curr Nutr Rep. 2017;6(2):148-156. doi:10.1007/s13668-017-0201-2

104. Spill MK, Callahan EH, Shapiro MJ, et al. Caregiver feeding practices and child weight outcomes: a systematic review. Am J Clin Nutr. 2019;109(Supplement 1):990S-1002S. doi:10.1093/ajen/nqy276

105. Pearce J, Taylor MA, Langley-Evans SC. Timing of the introduction of complementary feeding and risk of childhood obesity: A systematic review. Int J Obes. 2013;37(10):12951306. doi:10.1038/ijo.2013.99

106. Moorcroft KE, Marshall JL, McCormick FM. Association between timing of introducing solid foods and obesity in infancy and childhood: A systematic review. Matern Child Nutr. 2011;7(1):3-26. doi:10.1111/j.1740-8709.2010.00284.x

107. Zheng JS, Liu H, Zhao YM, et al. Complementary feeding and childhood adiposity in preschool-aged children in a large Chinese cohort. J Pediatr. 2015;166(2):326-331.e2. doi:10.1016/j.jpeds.2014.11.010

108. Seach KA, Dharmage SC, Lowe AJ, Dixon JB. Delayed introduction of solid feeding reduces child overweight and obesity at 10 years. Int J Obes. 2010;34(10):1475-1479. doi:10.1038/ijo.2010.101

109. Bainbridge RR, Mimouni FB, Landi T, Crossman M, Harris L, Tsang RC. Effect of rice cereal feedings on bone mineralization and calcium homeostasis in cow milk formula fed infants. J Am Coll Nutr. 1996;15(4):383-388. doi:10.1080/07315724.1996.10718613

110. Jonsdottir OH, Thorsdottir I, Hibberd PL, et al. Timing of the Introduction of Complementary Foods in Infancy: A Randomized Controlled Trial. Pediatrics. 2012;130(6):1038-1045. doi:10.1542/peds.2011-3838

111. Jonsdottir OH, Kleinman RE, Wells JC, et al. Exclusive breastfeeding for 4 versus 6 months and growth in early childhood. Acta Paediatr. 2014;103(1):105-111. doi:10.1111/apa.12433 
112. Cohen RJ, Brown KH, Canahuati J, Landa Rivera L, Dewey KG. Effects of age of introduction of complementary foods on infant breast milk intake, total energy intake, and growth: a randomised intervention study in Honduras. Lancet. 1994;343:288-293.

113. Dewey KG, Cohen RJ, Brown KH, Rivera LL. Age of introduction of complementary foods and growth of term, low-birth-weight, breast-fed infants: a randomized intervention study in Honduras. Am J Clin Nutr. 1999;69:679-686.

https://academic.oup.com/ajcn/article/69/4/679/4737375.

114. Moschonis G, de Lauzon-Guillain B, Jones L, et al. The effect of early feeding practices on growth indices and obesity at preschool children from four European countries and UK schoolchildren and adolescents. Eur J Pediatr. 2017;176(9):1181-1192.

doi:10.1007/s00431-017-2961-5

115. Identifying patients at risk: ADA's definitions for nutrition screening and nutrition assessment. Council on Practice (COP) Quality Management Committee. J Am Diet Assoc. 1994;94(8):838-839. doi:10.1016/0002-8223(94)92357-4

116. Northstone K, Emmett P, Nethersole F. The effect of age of introduction to lumpy solids on foods eaten and reported feeding difficulties at 6 and 15 months. J Hum Nutr Diet. 2001;14(1):43-54.

117. Coulthard H, Harris G, Emmett P. Delayed introduction of lumpy foods to children during the complementary feeding period affects child's food acceptance and feeding at 7 years of age. Matern Child Nutr. 2009;5(1):75-85. doi:10.1111/j.1740-8709.2008.00153.x

118. Hollis J, Crozier S, Inskip H, Cooper C, Godfrey K, Robinson S. Age at introduction of solid foods and feeding difficulties in childhood: findings from the Southampton Women's Survey. Br J Nutr. 2016;116(4):743-750. doi:10.1017/S0007114516002531

119. Mehta KC, Specker BL, Bartholmey S, Giddens J, Ho ML. Trial on Timing of Introduction to Solids and Food Type on Infant Growth. Pediatrics. 1998;102(3 Part 1):569-573. doi:10.1542/peds.102.3.569

120. Rolland-Cachera M, Deheeger M, Bellisle F. Increasing prevalence of obesity among 18year-old males in Sweden: evidence for early determinants. Acta Paediatr. 1999;88(4):365-367. doi:10.1111/j.1651-2227.1999.tb01123.x

121. Hörnell A, Lagström H, Lande B, Thorsdottir I. Protein intake from 0 to 18 years of age and its relation to health: a systematic literature review for the 5 th Nordic Nutrition Recommendations. Food Nutr Res. 2013;57(1). doi:10.3402/fnr.v57i0.21083

122. Heinig J, Nommsen LA, Peerson JM, Lonnerdal B, Dewey KG. Intake and growth of breast-fed and formula-fed infants in relation to the timing of introduction of complementary foods: the DARLING study. Acta Paediatr. 1993;82:999-1006.

123. Institute of Medicine (US) Committee on Nutritional Status During Pregnancy and Lactation. Nutrition during Lactation: Milk Volume. Washington (DC): National Academies Press (US); 1991. https://www.ncbi.nlm.nih.gov/books/NBK235589/. Accessed March 23, 2021.

124. Van Rossem L, Jong JCK, Looman CWN, et al. Weight change before and after the introduction of solids: Results from a longitudinal birth cohort. Br J Nutr. 2013;109(2):370-375. doi:10.1017/S0007114512001055

125. Huh SY, Rifas-Shiman SL, Taveras EM, Oken E, Gillman MW. Timing of solid food introduction and risk of obesity in preschool-aged children. Pediatrics. 2011;127(3):e544e551. doi:10.1542/peds.2010-0740

126. Harris G, Mason S. Are There Sensitive Periods for Food Acceptance in Infancy? Curr 
Nutr Rep. 2017;6(2):190-196. doi:10.1007/s13668-017-0203-0

127. Illingworth RS, Lister J. The critical or sensitive period, with special reference to certain feeding problems in infants and children. J Pediatr. 1964;65(6 (Part 1)):839-848.

128. Cooke LJ, Wardle J, Gibson EL, Sapochnik M, Sheiham A, Lawson M. Demographic, familial and trait predictors of fruit and vegetable consumption by pre-school children. Public Health Nutr. 2004;7(2):295-302. doi:10.1079/PHN2003527

129. Skinner JD, Carruth BR, Bounds W, Ziegler P, Reidy K. Do Food-Related Experiences in the First 2 years of Life Predict Dietary Variety in School-Aged Children? J Nutr Educ Behav. 2002;34(6):310-315.

130. Harris G, Coulthard H. Early Eating Behaviours and Food Acceptance Revisited: Breastfeeding and Introduction of Complementary Foods as Predictive of Food Acceptance. Curr Obes Rep. 2016;5(1):113-120. doi:10.1007/s13679-016-0202-2

131. Blissett J, Bennett C, Donohoe J, Rogers S, Higgs S. Predicting Successful Introduction of Novel Fruit to Preschool Children. J Acad Nutr Diet. 2012;112(12):1959-1967. doi:10.1016/j.jand.2012.08.014

132. Liberali R, Kupek E, Assis MAA de. Dietary Patterns and Childhood Obesity Risk: A Systematic Review. Child Obes. 2020;16(2):70-85. doi:10.1089/chi.2019.0059

133. Gillman Matthew, Ludwig David. How Early Should Obesity Prevention Start? N Engl J Med. 2013;369(23):2173-2175.

134. Birch LL, Doub AE. Learning to eat: birth to age 2 y. Am J Clin Nutr. 2014;99(suppl):723S-8S. doi:10.3945/ajcn.113.069047

135. Nutrition for healthy term infants. Paediatr Child Health. 1998;3(2):109-112. doi:10.1093/pch/3.2.109

136. American Academy of Pediatrics. Infant Food and Feeding. https://www.aap.org/enus/advocacy-and-policy/aap-health-initiatives/HALF-Implementation-Guide/AgeSpecific-Content/Pages/Infant-Food-and-Feeding.aspx. Accessed March 18, 2021.

137. Carsley S, Borkhoff CM, Maguire JL, et al. Cohort profile: The Applied Research Group for Kids (TARGet Kids!). Int J Epidemiol. 2015;44(3):776-788. doi:10.1093/ije/dyu123

138. Government of Canada. Canadian Community Health Survey . https:/www.canada.ca/en/health-canada/services/food-nutrition/food-nutritionsurveillance/health-nutrition-surveys/canadian-community-health-survey-cchs.html. Published 2017. Accessed July 8, 2020.

139. Randall Simpson J, Keller HH, Rysdale LA, Beyers JE. Nutrition Screening Tool for Every Preschooler (NutriSTEP ${ }^{\mathrm{TM}}$ ): Validation and test-retest reliability of a parentadministered questionnaire assessing nutrition risk of preschoolers. Eur J Clin Nutr. 2008;62(6):770-780. doi:10.1038/sj.ejcn.1602780

140. Randall Simpson J, Gumbley J, Whyte K, et al. Development, reliability, and validity testing of Toddler NutriSTEP: a nutrition risk screening questionnaire for children 18-35 months of age. Appl Physiol Nutr Metab. 2015;40:877-886. doi:10.1139/apnm-2015-0048

141. Flegal KM, Ogden CL. Childhood obesity: are we all speaking the same language? . Adv Nutr. 2011;2(2):159S-166S. doi:10.3945/an.111.000307

142. World Health Organization. WHO child growth standards based on length/height, weight and age. Acta Paediatr. 2006;450(Suppl):76-85.

143. De Onis M, Lobstein T. Defining obesity risk status in the general childhood population: Which cut-offs should we use? Int J Pediatr Obes. 2010;5:458-460. doi:10.3109/17477161003615583 
144. Bates D, Mächler M, Bolker BM, Walker SC. Fitting linear mixed-effects models using lme4. J Stat Softw. 2015;67(1):1-48.

145. Touloumis A. R Package multgee: A Generalized Estimating Equations Solver for Multinomial Responses. J Stat Softw. 2014;64(8):1-14.

146. Harrell F. Regression Modeling Strategies with Applications to Linear Models, Logistic and Ordinal Regression and Survival Analysis. 2nd ed. New York: Springer; 2015.

147. Perperoglou A, Sauerbrei W, Abrahamowicz M, Schmid M. A review of spline function procedures in R. BMC Med Res Methodol. 2019;19(1):46. doi:10.1186/s12874-019-06663

148. Lenth R, Singmann H, Love J, Buerkner P, Herve M. The comprehensive R Archive Network: Package 'emmeans.' doi:10.1080/00031305.1980.10483031

149. van Buuren S, Groothuis-Oudshoorn K. mice: Multivariate imputation by chained equations in R. J Stat Softw. 2011;45(3):1-67. doi:10.18637/jss.v045.i03

150. R Core Team. R: A language and enviornment for statistical computing. 2020. https://www.r-project.org/.

151. World Health Organization. WHO Growth reference 5-19 years. WHO. https://www.who.int/growthref/who2007_weight_for_age/en/. Published 2007. Accessed September 23, 2020.

152. Gingras V, Aris IM, Rifas-Shiman SL, Switkowski KM, Oken E, Hivert MF. Timing of complementary feeding introduction and adiposity throughout childhood. Pediatrics. 2019;144(6). doi:10.1542/peds.2019-1320 